\title{
MAPA DE MATORRALES DE LA RIOJA: REVISIÓN Y METODOLOGÍA
}

\section{Map of scrub communities in La Rioja (Spain): Review and methods}

\author{
Rafael Fernández Aldana ${ }^{1 *}$, César López Leiva ${ }^{2}$, Teresa Bañares García ${ }^{3}$ \\ ${ }^{1}$ Dirección General de Medio Natural. Gobierno de La Rioja. \\ ${ }^{2}$ Departamento de Sistemas y Recursos Naturales. Universidad Politécnica de Madrid. \\ ${ }^{3}$ Tragasatec. \\ Identificación ORCID de los autores y e.mail \\ Rafael Fernández Aldana: http://orcid.org/0000-0002-7868-2342. e-mail: raldana54@gmail.com \\ César López Leiva: http://orcid.org/0000-0002-1186-2680. e-mail: cesar.lopez@upm.es \\ Teresa Bañares García: http://orcid.org/0000-0003-2269-7403. e-mail: teresabanares@gmail.com \\ *Autor corresponsal
}

Recibido: 27-07-2018. Aceptado: 02-09-2018. Fecha de publicación on-line: 19/11/2018

Citation / Cómo citar este artículo: Fernández Aldana, R., López Leiva, C., Bañares García, T. (2018). Mapa de matorrales de La Rioja: revisión y metodología. Pirineos, 173, e040. https://doi.org/10.3989/pirineos.2018.173007

RESUMEN: Se aborda una actualización del mapa de matorrales de La Rioja, que tiene como antecedente principal el mapa de Arizaleta, Fernández Aldana y Lopo (1990). Para soslayar las dificultades conceptuales y operativas de una cartografía de este tipo de cubiertas vegetales, se propone la definición de 16 tipos de "matorrales dominantes", con su correspondiente asignación territorial potencial y la confección de un nuevo mapa en 2018. Se consideran tres categorías: uniformes (mono u oligoespecíficos), mixtos complejos (pluriespecíficos) y combinaciones entre dos tipos. Asimismo, excluyendo de esos 16 dominios teóricos las superficies arboladas mediante la intersección con el Mapa de Bosques de La Rioja (2015), se han obtenido las áreas de distribución de cada tipo, allí donde hay efectiva presencia de cubiertas no arboladas, complejo matorral-pastos. Se indica el procedimiento propuesto para el registro y codificación de las agrupaciones y, para cada uno de los 16 tipos de matorral, se reseña en este trabajo su distribución geográfica, relacionándola con los ámbitos de pisos bioclimáticos, tipos climático-estructurales de vegetación y su correspondencia con clasificaciones propuestas para el conjunto de España. Las cartografias resultantes son la base para una actualización permanente, basada en la intensificación de los trabajos de campo y en el uso de imágenes aéreas de creciente resolución.

PALABRAS CLAVE: Matorrales; cartografía; La Rioja.

ABSTRACT: This paper presents an updated map of shrubs in La Rioja, with the main precedent cartography of Arizaleta, Fernández Aldana y Lopo (1990). In order to avoid the conceptual and operational difficulties inherent to the mapping of this type of plant covers, we propose the definition of 16 types of "dominant shrublands" with their corresponding potential allocation and the production of a new map in 2018. Three categories are considered: uniform (mono- or oligospecific), complex mixtures (plurispecific) and combinations of two types. Additionally and excluding the forested surfaces from those 16 domains by means of intersecting them with the Mapa de Bosques de La Rioja 


\section{• • R. FERNÁNDEZ ALDANA, C. LÓPEZ LEIVA, T. BAÑARES GARCÍA}

(2015), we have obtained the distribution areas of every type, wherever there is effective presence of non arboreous plant covers (the complex shrublands-grasslands). We indicate the proposed procedure for the recording and encoding of plant communities. Moreover, we describe the geographic distribution of the 16 shrub types and their correspondence with other classifications valid for the whole Spain. The resulting map are the base for an ongoing updating, supported by the intensification of field surveys and the use of the increasing-resolution aerial imagery.

KEYWORDS: Scrubs, mapping, La Rioja.

\section{Introducción}

\subsection{La importancia de los matorrales en La Rioja}

A pesar de haber sido a menudo relegados por el imaginario forestal a papeles marginales en la gestión de los ecosistemas, los matorrales ejercen una función ecológica muy importante, más si tenemos en cuenta su significación superficial. Dentro de estas funciones pueden destacarse (San Miguel Ayanz et al., 2004): la protección del suelo frente a la erosión en situaciones difíciles para la vegetación arbórea y, en ocasiones, con la misma eficacia en la regulación del ciclo hídrico, su aportación a la biodiversidad, los beneficios derivados de su explotación cinegética, ganadera o apícola, etc.

En La Rioja, el complejo "matorral-pastos", es decir, las comunidades vegetales de leñosas bajas, herbáceas o mezcla de ambas, alcanzan 131.265 hectáreas (Mapa de Bosques de La Rioja, IDErioja 2015, Gobierno de La Rioja), lo que representa el $26 \%$ de la superficie total regional, y el 42,3\% del conjunto de la superficie forestal, con un peso muy semejante al de los bosques.

\subsection{Precisiones sobre el concepto de "matorrales"}

Antes de explicar la metodología aplicada en la elaboración del mapa de matorrales de La Rioja es necesario aclarar el concepto de "matorral" usado en este trabajo, que ha permitido definir distintos tipos, así como su diferenciación del de "arbustedo".

"Matorral" sería la comunidad vegetal definida por el predominio de matas en el estrato superior (el más alto con espesura) y "arbustedo" una variante de matorral, en sentido amplio, con matas dominantes de talla arbustiva (Ruiz de la Torre, 1981, 1990), al menos potencialmente como más frecuente. Por tanto, las formaciones no arboladas leñosas o "matorrales", en la acepción que emplearemos, comprenden unidades de cubierta vegetal de tallas subarbustivas $(1,5-3 \mathrm{~m})$ a bajas $(<0,5 \mathrm{~m})$.

"Arbusto" debe entenderse, en contraposición, como "planta leñosa, de vida plurianual, con diferenciación de tronco y copa en su parte aérea, es decir, ramificada a una cierta altura sobre el suelo (generalmente a más de $1 \mathrm{~m}$ ) y de talla comprendida entre 3 y 7 m" (Ruiz de la Torre, 1990). Además, la estructura horizontal de un arbustedo o comunidad de arbustos se caracteriza por una mayor posibilidad de individualización de ejemplares, mientras que los matorrales, propiamente dichos y con la acepción utilizada en este trabajo, se encuentran con frecuencia como elementos matriciales o esenciales del paisaje, subsumidos en formaciones de carácter continuo.

Con todo, la delimitación precisa entre arbustedos y matorrales puede ser, en algunos casos, controvertida (por ejemplo, en los bujedos o en los escobonales, con tallas dominantes que pueden alcanzar el rango arbustivo). También son frecuentes en otros casos las combinaciones (por ejemplo, matorrales xerófilos con coscojares), pero se ha adoptado un criterio operativo para permitir la representación cartográfica diferenciada, considerando la frecuencia estadísticamente modal en la fisonomía de cada uno de los tipos.

El concepto de "matorral" incluye un conjunto de tipos de unidades de vegetación que, de inicio, es heterogéneo, lo que aparentemente complica la asignación de un nombre específico. La caracterización y denominación de las unidades de matorral puede hacerse atendiendo a diversos criterios como, por ejemplo, dominancia, forma de inserción, talla dominante, densidad del estrato dominante o significativo, estratificación, significación dinámica, rangos de extensión superficial o adscripción mesológica.

En este trabajo el criterio principal ha sido el de la dominancia de sus especies integrantes, diferenciando entre matorrales uniformes (mono u oligoespecíficos) y matorrales mixtos complejos (pluriespecíficos). Es frecuente, también, la presencia de combinaciones de algunos de los tipos incluidos en estos dos grandes grupos en una misma porción de territorio, formando mosaicos intrincados o mezclas de las dos categorías.

\subsection{Problemática de la cartografía de matorrales}

La elaboración de los mapas de distribución de matorrales se enfrenta a diversas dificultades específicas entre las que se pueden citar las siguientes:

- La caracterización de los matorrales y, en particular, la propia denominación de estas comunidades leñosas o con predominio de leñosas no arbóreas constituye una de sus dificultades intrínsecas, soslayable en la medida en que la variabilidad de las posibles combinaciones quede sistematizada reduciendo al mínimo la arbitrariedad en las clasificaciones.

- Desde el punto de vista espacial, los matorrales presentan una mayor complejidad en su delimitación sobre el terreno por la mayor frecuencia de mezclas, micromosaicos, predominios locales de especies integrantes en comunidades mixtas, etc. Los gradientes y transiciones son norma común en la 
distribución territorial de los matorrales, lo que dificulta el trazado de límites nítidos.

- A esa complejidad de elevada diversidad intrínseca y de variabilidad espacial (suelos y orientaciones) se une la variabilidad temporal (complejidad de caracterización a causa de su rápida evolución por incendios, desbroces, presión ganadera...) derivada de causas naturales o antrópicas. Para cada tipo de matorral, también puede haber distintas manifestaciones, estados evolutivos o de madurez, es decir, la posición dinámica puede ser sutil o nítidamente variable en función de los rangos de variación de los atributos de estructura (talla, densidad) o de la posible diversidad de integrantes en la composición.

- Por su mayor adaptabilidad, la adscripción mesológica de los matorrales puede no ser unívoca, a diferencia de lo que es general con las comunidades arbóreas. Algunos tipos de matorrales son comunes a territorios que pueden asignarse a dominios potenciales de tipos estructurales arbolados distintos. Las comunidades arbóreas de cabecera de los Tipos Climático-Estructurales (Ruiz de la Torre, 1990, 2000) que representan la fisonomía y estructura de las agrupaciones más maduras (lo que, en otras aproximaciones conceptuales, se denominan comunidades climácicas) tienen una vinculación más unívoca, como es el caso de La Rioja, con los hayedos (Tipo de los Bosques caducifolios), los pinares de Pinus sylvestris (Tipo de las Coníferas aciculifolias orófilas) o los robledales (Tipo de los Bosques subesclerófilos). Si entre estos tipos las fronteras son a menudo difíciles de trazar a escalas de detalle, con los matorrales esta dificultad, como ya se ha apuntado, es aún más acentuada.

Por todo ello, la fotointerpretación de los matorrales, en comparación con las masas arboladas, ofrece menos oportunidades para el reconocimiento nítido sobre las imágenes disponibles, derivándose una gran dificultad para la realización de una cartografía de este tipo de formaciones vegetales que obstaculiza un barrido sistemático del territorio, problema que se pretende reducir a través de la delimitación del ámbito de lo que se ha definido como matorral dominante.

\section{4. Área de estudio. Antecedentes de la cartografia de matorrales en La Rioja}

El ámbito territorial de este trabajo abarca la totalidad de la Comunidad Autónoma de La Rioja que tiene una superficie de $5.045 \mathrm{~km}^{2}$ y se extiende sobre la región natural limitada al norte por el río Ebro y al sur por la Cordillera Ibérica. Está estructurada en siete cuencas hidrográficas, Tirón, Oja, Najerilla, Iregua, Leza-Jubera, Cidacos y Alhama, y comprende dos espacios geográficos claramente diferenciados: las tierras bajas, predominantemente agrícolas, del Valle del Ebro al norte; y la zona montañosa del Sistema Ibérico septentrional al sur, de marcado carácter forestal. En el ámbito montano pueden distinguirse las zonas de alta montaña a partir de los 1.700$1.800 \mathrm{~m}$, aproximadamente, y las zonas de montaña media, entre dicha cota y el contacto de los piedemontes con las tierras agrícolas del Valle del Ebro, en torno a los 600700 metros.

En el año 1990, Arizaleta, Fernández Aldana y Lopo publicaron el trabajo "Los matorrales de La Rioja", en donde se definían diversas clases de matorrales finalmente cartografiadas en un mapa general a escala 1:400.000. Dentro de este mapa las formaciones leñosas abarcaban la totalidad de la geografía riojana a modo del "dominio de cada tipo de matorral a escala regional" que se extendía por grandes recintos y también incluían otro tipo de usos, como bosques, cultivos, etc.

En el presente trabajo se actualiza este estudio con apoyo de una base cartográfica mucho más detallada según las ortofotos de los años 2009 y 2014 (IDErioja, Gobierno de La Rioja) y se profundiza en el concepto de "matorral dominante" y su aplicación como metodología para facilitar la cartografía de las formaciones de matorral.

\section{Material y métodos}

\subsection{Concepto de matorral dominante}

Una vez sentadas las particularidades de los matorrales como unidades identificables y la complejidad frecuente de su cartografía, la fotointerpretación y, sobre todo, el barrido completo sobre el terreno presenta diversas dificultades de tipo operativo. Con el objetivo de poder avanzar en su delimitación, se ha propuesto una clasificación preliminar de los matorrales de La Rioja a partir del concepto de matorral dominante.

En aplicación de este concepto, una cierta porción de territorio se asigna al "dominio" de un tipo de matorral cuando éste constituye, dentro de las cubiertas vegetales de esta categoría y en posiciones dinámicas de madurez intermedia, la manifestación más probable y de nivel evolutivo mayor dentro del conjunto de los matorrales de posible concurrencia. Es decir, el matorral dominante constituiría la cubierta vegetal no arbolada potencialmente más frecuente dados ciertos rangos de condiciones del medio físico y de explotación ecológica natural o artificial moderada.

Entendido así, el matorral dominante sería la "cabecera" representativa a nivel territorial, independientemente de que su presencia sea real o no en la actualidad, y como una expresión del "óptimo" en los niveles intermedios y bajos (excluyendo, por tanto, los bosques y los arbustedos). Se entenderá por "óptimo" el que mejor representa el aprovechamiento máximo de los recursos de agua, energía y nutrientes en estos niveles de madurez.

Los matorrales dominantes se corresponden con unos márgenes amplios en cuanto a características ecológicas, dada la gran adaptabilidad mencionada de este tipo de formaciones, motivo por el cual ocupan grandes extensio- 
nes y pueden incluir distintas variantes que responden a condiciones particulares de estación (orientación, humedad edáfica, etc.) y son resultado de distintos tipos e intensidades de presiones antrópicas.

\subsection{Tipos de matorral dominante}

Para la definición de los tipos de matorral dominante se han elegido las especies principales que caracterizan por predominio los tipos o agrupaciones que representan a cada ámbito mesológico (pisos bioclimáticos, sustratos, niveles evolutivos...) y, sobre todo, que dominan superficialmente (criterio de fracción de cabida cubierta relativa) la vegetación leñosa. En el caso de la presencia de varias especies dominantes, se han definido agrupaciones de matorral con denominación genérica (matorrales de alta montaña, matorrales xerófilos de media montaña...).

De este modo, y atendiendo, principalmente, a su significación ecológica y a su importancia superficial, se han establecido 16 tipos o agrupaciones de matorral, en tres de los cuales se han considerado dos variantes. Los tipos de matorral quedan agrupados por categorías de complejidad en cuanto al número de especies principales que los integran del siguiente modo:

1. Matorrales mono u oligoespecíficos (7 tipos):

- Bujedos de Buxus sempervirens.

- Brezales mayores s.1., de Erica australis, Erica arborea y/o Erica scoparia. Se han agrupado en dos variantes:

- Alta y media montaña, dominados por Erica australis y presencia significativa de Erica arborea.

- Media montaña y piedemonte, con predominio de Erica arborea y, localmente, de Erica scoparia.

- Escobonales s.1., formados por Cytisus scoparius y/o Genista florida, que abarcan escobonales de media montaña, mesófilos, y escobonales en zonas de transición, submesófilos o subxerófilos.

- Estrepales de Cistus laurifolius.

- Aulagares de Genista scorpius.

- Jarales bajos de Cistus albidus y, en menor medida, de Cistus salviifolius, con dos variantes:

- Sin presencia de Genista scorpius.

- Con presencia de Genista scorpius.

- Romerales de Rosmarinus officinalis.

2. Matorrales mixtos complejos (pluriespecíficos) (6 tipos):

- Matorrales de alta montaña, formados mayoritariamente por biércol (Calluna vulgaris) y enebro rastrero (Juniperus communis ssp. alpina), con enclaves de piorno (Cytisus oromediterraneus) y penetraciones de brezo (Erica australis).

- Biercolares, agrupaciones de brecina y brezos bajos (biércoles): Calluna vulgaris, Erica vagans y, en menor medida, con Erica cinerea.
- Matorrales xerófilos de media montaña, extendidos, exclusivamente, por la cuenca del AlhamaLinares y formados por salvio-esplegares (Salvia lavandulifolia/Lavandula latifolia), aulagares (Genista scorpius) y tomillares (Thymus sp.), junto con la presencia frecuente de romerales (Rosmarinus officinalis), con predominio local de una o más agrupaciones de las enumeradas.

- Matorrales xerófilos basales del Valle del Ebro y constituidos por lasto-timo-aulagares y mezclas de tomillares (Thymus sp. y géneros fisonómicamente afines) y aulagares (Genista scorpius), con abundancia de lastonares (Brachypodium retusum).

- Matorrales gipsófilos, en donde se incluyen arnachales (Ononis tridentata) y matorrales gipsófilos mixtos-estepas gipsófilas y lasto-timo-aulagares hiperxerófilos en transición a gipsófilos.

- Matorrales halófilos y nitrófilos del Valle del Ebro, en donde se incluyen matorrales halonitrófilos como sisallares (Salsola vermiculata), ontinares (Artemisia herba-alba), bojares (Artemisia campestris, glutinosa) y orgazales (Artriplex halimus), así como matorrales halohidrófilos como espartizales-albardinales halohidrófilos (Lygeum spartum) y sosares vivaces (Suaeda vera) y terofíticos (Salicornia ramosissima).

3. Combinaciones de tipos anteriores en mezclas o micromosaicos (3 tipos):

- Escobonales-brezales mayores, agrupaciones a modo de transición entre brezales y escobonales o como posible sustitución de los escobonales por degradación. Se han agrupado en dos variantes en función del tipo de brezo dominante:

- Alta y media montaña, mesófilos, con Erica arborea y, ocasionalmente, con Erica australis.

- Media montaña y piedemonte, submesófilos o subxerófilos, con Erica scoparia en piedemonte y, en menor medida, Erica arborea.

- Biercolares-jarales bajos de piedemonte con Calluna vulgaris, Erica vagans y Cistus albidus como especies principales y con presencia de Cistus salviifolius.

- Brezales mayores-jarales bajos de piedemonte con Erica scoparia, Cistus albidus y, en menor medida, Erica arborea.

Además de estos tipos principales, en La Rioja existen otros tipos de matorrales con presencia residual o testimonial que, por tanto, no tienen la consideración de formaciones dominantes. Entre ellos pueden destacarse los siguientes:

- Tojares (Ulex europeus)

- Aulaginares/olaginares (Genista hispanica).

- Erizonales (Erinacea anthyllis).

- Escobillares (Dorycnium pentaphyllum)

El Anexo 1 recoge las correspondencias entre los tipos anteriormente definidos en este trabajo y la Taxono- 
mía de cubiertas vegetales no arboladas, propuesta por López Leiva $(2008,2018)$ para el conjunto del territorio español y que está sirviendo de base para la definición genérica de arbustedos, matorrales y pastos herbáceos en el Mapa Forestal de España a escala 1:25.000.

\subsection{Fotointerpretación de los matorrales dominantes}

Se plantea el trabajo en tres fases principales:

Fase I. Delimitación de los grandes espacios asignables a tipos de matorral dominante

Una vez definidos los tipos de matorral dominante, con 16 agrupaciones en total, en esta fase se ha elaborado el Mapa de Matorrales dominantes a partir de las ortofotos en color de La Rioja (años 2009 y 2014, IDErioja, Gobierno de La Rioja) que permite obtener una imagen general de la distribución de los tipos de matorral en el territorio.

Partiendo de la presencia contrastada o aproximada de cada agrupación en las fotografías aéreas, se ha trazado una línea envolvente de dichos recintos al margen de que puedan, lógicamente, englobar enclaves de otras agrupaciones, de extensión más reducida o mezcladas con la dominante. No se han considerado los recintos arbolados internos en cuanto a la caracterización territorial, salvo en el caso de la aparición de claros en los bosques que pueden ser asociados a espacios deforestados próximos.

Para la definición de los límites territoriales de estos grandes dominios, así como de las diferentes tipologías que los caracterizan, se han tenido en cuenta los siguientes criterios:

- Elección de las especies dominantes que caracterizan los tipos o agrupaciones representativas de las condiciones del medio (pisos bioclimáticos, sustratos, niveles evolutivos...) y, sobre todo, que dominan superficialmente (criterio de fracción de cabida cubierta relativa) como vegetación leñosa.

- Delimitación de superficies amplias, a modo de envolventes, en donde su presencia es dominante, al margen de la existencia de enclaves de otro tipo de agrupaciones, de extensión más reducida o mezcladas con la dominante.

- No consideración de los recintos arbolados internos en cuanto a la caracterización territorial, salvo en el caso de la aparición de claros en los bosques que pueden ser asociados a espacios deforestados próximos.

En los casos de duda en la fotointerpretación o en donde apenas existan espacios deforestados por la presencia mayoritaria de formaciones arbóreas y arbustivas, se han tenido en cuenta los siguientes criterios relativos a las características del territorio:

- Pisos bioclimáticos que, en La Rioja, tienen un elevado componente altitudinal (basal, piedemonte, montaña media, alta montaña) y longitudinal (mayor influencia oceánica en el oeste y mediterránea en el este), así como su relación con las etapas evolutivas o seriales de los bosques. La definición y denominación de los pisos es la de Rivas-Martínez (1987) y Rivas-Martínez y colaboradores (2007), con ligeras adaptaciones territoriales en el trazado de sus límites.

- Características fisiográficas del territorio que modifican el ámbito macroclimático anterior, tales como la orientación (solana/umbría) y su posición respecto a los vientos dominantes del noroeste (laderas y fondos de valle influenciados por el Efecto Foehn).

- Litología del terreno en sus variantes silícea y caliza, junto con los enclaves de carácter azonal (yesos y sales) que pueden determinar totalmente la composición y la estructura de las formaciones leñosas.

- Usos actuales y pretéritos del territorio que modifican las etapas evolutivas potenciales: los terrenos antiguamente cultivados con presencia masiva de aulagares dentro de entornos dominados por otras especies (bujedos, romerales...), zonas afectadas por el reiterado uso del fuego para la mejora de pastos (estrepales en la cuenca del Leza-Jubera), o por la presión ganadera (biercolares en los pastizales de cumbre y majadales).

- Deforestación histórica y generalizada de amplios territorios acompañada de una degradación de los suelos en ámbitos predominantemente mediterráneos o submediterráneos (matorrales xerófilos de media montaña con presencia de romerales en la cuenca del Alhama- Linares).

También al delimitar la envolvente de estos matorrales dominantes se ha tenido en cuenta la jerarquía de algunas formaciones respecto de otras, primándose aquellas agrupaciones más representativas de determinados pisos bioclimáticos en relación con otras formaciones de carácter más ubicuo. Uno de los ejemplos más significativos son los aulagares que se extienden por una gran parte del territorio riojano asociados a la colonización de terrenos de cultivo abandonados. O también, en menor medida, los biercolares, en muchos casos ligados a zonas pastoreadas que se intercalan dentro de los grandes espacios de los matorrales dominantes. Fase II. Tipificación de los espacios desarbolados a
partir del Mapa de Bosques de La Rioja

A partir del Mapa de Bosques de La Rioja (IDErioja 2015, Gobierno de La Rioja), en donde se representan las masas arboladas y los arbustedos, se ha procedido a su solape con el Mapa de Matorrales dominantes, asociando a cada espacio forestal no arbolado el tipo de matorral correspondiente. Este proceso ha permitido definir la cubierta vegetal de estas parcelas desarboladas dentro del complejo denominado "matorral- pastos". Se trata 


\section{6 • R. FERNÁNDEZ ALDANA, C. LÓPEZ LEIVA, T. BAÑARES GARCÍA}

de un espacio ligado a una dinámica evolutiva entre ambas cubiertas, sea de carácter progresivo, como consecuencia de la propia regeneración natural de la vegetación a través de la etapa de matorral, o sea de carácter regresivo, a causa de los incendios forestales o de las actuaciones de desbroce de los propios matorrales para la prevención de incendios y/o mejora de los pastos herbáceos extensivos.

Fase III. Caracterización de los espacios de matorral dominante. Elaboración de mapas de distribución de las agrupaciones de matorral

A partir de la delimitación y caracterización de estas teselas desarboladas, se analizan con mayor profundidad los grandes dominios con el fin de conseguir un mayor detalle en la cartografía mediante una fotointerpretación más pormenorizada y basada en los datos obtenidos a través del trabajo de campo, de intensidad proporcional a los medios disponibles.

De este modo, se pueden subdividir las teselas anteriores considerando la posibilidad de mezclas entre todas las agrupaciones descritas y la existencia de enclaves de unas agrupaciones dentro de otras. También puede tenerse en cuenta, si se dispone de datos, la presencia de otras agrupaciones de matorral más minoritarias determinadas por circunstancias naturales (sustrato, orientación, pendiente...) o por influencia humana (antiguos cultivos, car- ga ganadera, quemas...). En el caso de no disponer de nueva información sobre la tesela, la agrupación asociada a esta reflejará, por defecto, el tipo correspondiente de matorral dominante.

Como resultado final de esta fase, en cada tesela segregada se contaría con información de cabecera del Dominio de matorral o Matorral dominante (MD), junto con la agrupación de matorral (AM) efectivamente existente, acompañada de las especies principales que componen la citada agrupación registradas en hasta tres campos de la base de datos asociada (Mat1, Mat2 y Mat3).

En la Tabla 1 se reflejan, a modo de ejemplo para diversos tipos de formaciones, los registros para cada tesela, recinto o polígono que se incluirían en la base de datos del mapa de agrupaciones de matorral.

De este modo se han obtenido una serie de mapas de distribución específicos para cada una de las agrupaciones definidas, cada uno de los cuales refleja el territorio en donde están presentes, sea como matorral exclusivamente dominante, sea en mezcla con otro tipo de agrupación, o sea como acompañante de otras dominantes. A partir de estos mapas de distribución territorial real es posible abordar con mayor profundidad su relación con los factores ambientales que los determinan, sin dejar de lado la elevada importancia del factor humano en unas formaciones vegetales que, en su mayor parte, tienen una significación serial. Estos mapas se reflejan en el capítulo sobre "Los matorrales y los pisos bioclimáticos" (Figuras 2-17).

Tabla 1.

Agrupación de tipo monoespecífico (ejemplo)

Monospecific community type (example)

\begin{tabular}{|l|l|l|l|l|}
\hline \multicolumn{1}{|c|}{ MD } & \multicolumn{1}{|c|}{ AM } & Mat1 & Mat2 & Mat3 \\
\hline Estrepales & Estrepales & 2511 (Cistus laurifolius) & & \\
\hline
\end{tabular}

Agrupación pluriespecífica (ejemplo)

Plurispecific community type (example)

\begin{tabular}{|l|l|l|l|l|}
\hline \multicolumn{1}{|c|}{ MD } & \multicolumn{1}{|c|}{ AM } & \multicolumn{1}{c|}{ Mat1 } & \multicolumn{1}{c|}{ Mat2 } & \multicolumn{1}{c|}{ Mat3 } \\
\hline $\begin{array}{l}\text { Matorrales de alta } \\
\text { montaña }\end{array}$ & $\begin{array}{l}\text { Matorrales de alta } \\
\text { montaña }\end{array}$ & 2259 (Calluna vulgaris) & $\begin{array}{l}212 \text { (Juniperus } \\
\text { communis ssp. alpina) }\end{array}$ & 2252 (Erica australis) \\
\hline
\end{tabular}

Mezcla de agrupaciones (ejemplo)

Mixed communities (example)

\begin{tabular}{|l|l|l|l|l|}
\hline \multicolumn{1}{|c|}{ MD } & \multicolumn{1}{|c|}{ AM } & Mat1 & Mat2 & Mat3 \\
\hline Aulagares & $\begin{array}{l}\text { Aulagares -jarales } \\
\text { bajos }\end{array}$ & 2432 (Genista scorpius) & 2515 (Cistus albidus) & \\
\hline
\end{tabular}

Otros tipos de matorral (ejemplo)

Other types of scrub communities (example)

\begin{tabular}{|c|l|l|l|l|}
\hline MD & \multicolumn{1}{|c|}{ AM } & \multicolumn{1}{|c|}{ Mat1 } & \multicolumn{1}{c|}{ Mat2 } & Mat3 \\
\hline Brezales mayores & Piornal & $\begin{array}{l}\text { 2311(Cytisus } \\
\text { scoparius })\end{array}$ & & \\
\hline
\end{tabular}




\section{Resultados}

\subsection{El Mapa de Matorrales dominantes de La Rioja (Mapa General)}

El resultado de la fase I es el Mapa de Matorrales dominantes (Figura 1) que representa los grandes dominios territoriales sin consideración de las posibles mezclas entre las diferentes agrupaciones definidas y acorde con la escala de representación. En la Tabla 2 se refleja una estimación de las superficies correspondientes a cada uno de los dominios de los tipos de matorral definidos, así como de su presencia real.

En la primera columna (Dominios), las superficies potenciales son netas y suman la totalidad de la superficie regional. En la segunda (Presencia), se indica la superficie en donde esa agrupación está presente de forma efectiva, bien sea como único integrante (p. ej., Bujedos), en mezcla con otro tipo (p. ej., Bujedos-aulagares), o como acompañante secundario en otra agrupación (que, en la notación propuesta para su registro en las bases de datos, adoptaría la forma de ejemplo Aulagares (Bujedos). Por ello, son cifras no coincidentes con la superficie total ocupada por cada uno de los tipos, ya que, en algunos casos, figura tan sólo como acompañante del dominante o compartiendo el territorio con otros.

Comparando ambas columnas, destacan, por un lado, los matorrales con un elevado porcentaje de presencia sobre su ámbito dominante por la existencia de amplias zo- nas deforestadas, como es el caso de los aulagares, romerales, matorrales xerófilos de media montaña o matorrales de alta montaña. En el lado opuesto se sitúan los matorrales con una presencia porcentual baja, sea por la presencia mayoritaria de terrenos de cultivo, como es el caso de los matorrales xerófilos basales en el Valle del Ebro, o de bosques, como es el caso de los brezales mayores, escobonales-brezales mayores o escobonales en las sierras occidentales. Un caso aparte sería el de los matorrales intrazonales, restringidos a enclaves poco aptos para el cultivo o las formaciones arbóreas.

\subsection{Los tipos de matorral y los pisos bioclimáticos (Mapas de distribución)}

En la Tabla 3 se incluyen las correspondencias entre los tipos definidos en la nueva cartografía de matorrales de La Rioja y los pisos bioclimáticos, los tipos climáticoestructurales (Ruiz de la Torre, 1990, 1998) y las cabeceras teóricas de los complejos evolutivos, es decir, cubiertas vegetales de mayor madurez esperables. En el caso de los matorrales, una parte de ellos se encuentran asociados de manera específica a estos ámbitos bioclimáticos pero su mayor amplitud ecológica en relación con los bosques determina que en algunos casos desborden sus límites.

A continuación, se describen los mapas de distribución territorial resultantes de la fase III (Figuras 2-17) de cada una de las agrupaciones de matorral definidas, refle-

Tabla 2. Estimación superficial de áreas potenciales de ocupación (dominios) por tipos de matorral y superficie efectiva dentro del dominio, excluyendo las áreas arboladas y los arbustedos. Fuente: Mapa elaborado.

Table 2. Surface assessment of potential occupation areas (domains) for each scrub community type and actual surface within their domains except forests and higher brushwoods. Source: Map produced.

\begin{tabular}{|l|c|c|}
\hline & Dominios (ha) & Presencia (ha) \\
\hline Matorrales de alta montaña & 3.377 & 9.195 \\
\hline Brezales mayores & 46.255 & 3.567 \\
\hline Escobonales-brezales mayores & 24.248 & 7.092 \\
\hline Escobonales & 50.504 & 4.853 \\
\hline Biercolares & 29.058 & 13.735 \\
\hline Bujedos & 12.433 & 1.524 \\
\hline Estrepales & 31.837 & 40.847 \\
\hline Biercolares- jarales bajos & 7.506 & 8.128 \\
\hline Aulagares & 66.940 & 8.953 \\
\hline Romerales & 16.128 & 247 \\
\hline Matorrales xerófilos de media montaña & 21.160 & 608 \\
\hline Brezales mayores-jarales bajos & 2.461 & 1.613 \\
\hline Jarales bajos & 2.889 & 2.178 \\
\hline Matorrales gipsófilos & 2.356 & 13.350 \\
\hline Matorrales halófilos y nitrófilos & 2.973 & 135.796 \\
\hline Matorrales xerófilos basales & 184.400 & \\
\hline TOTAL & 504.525 & \\
\hline
\end{tabular}




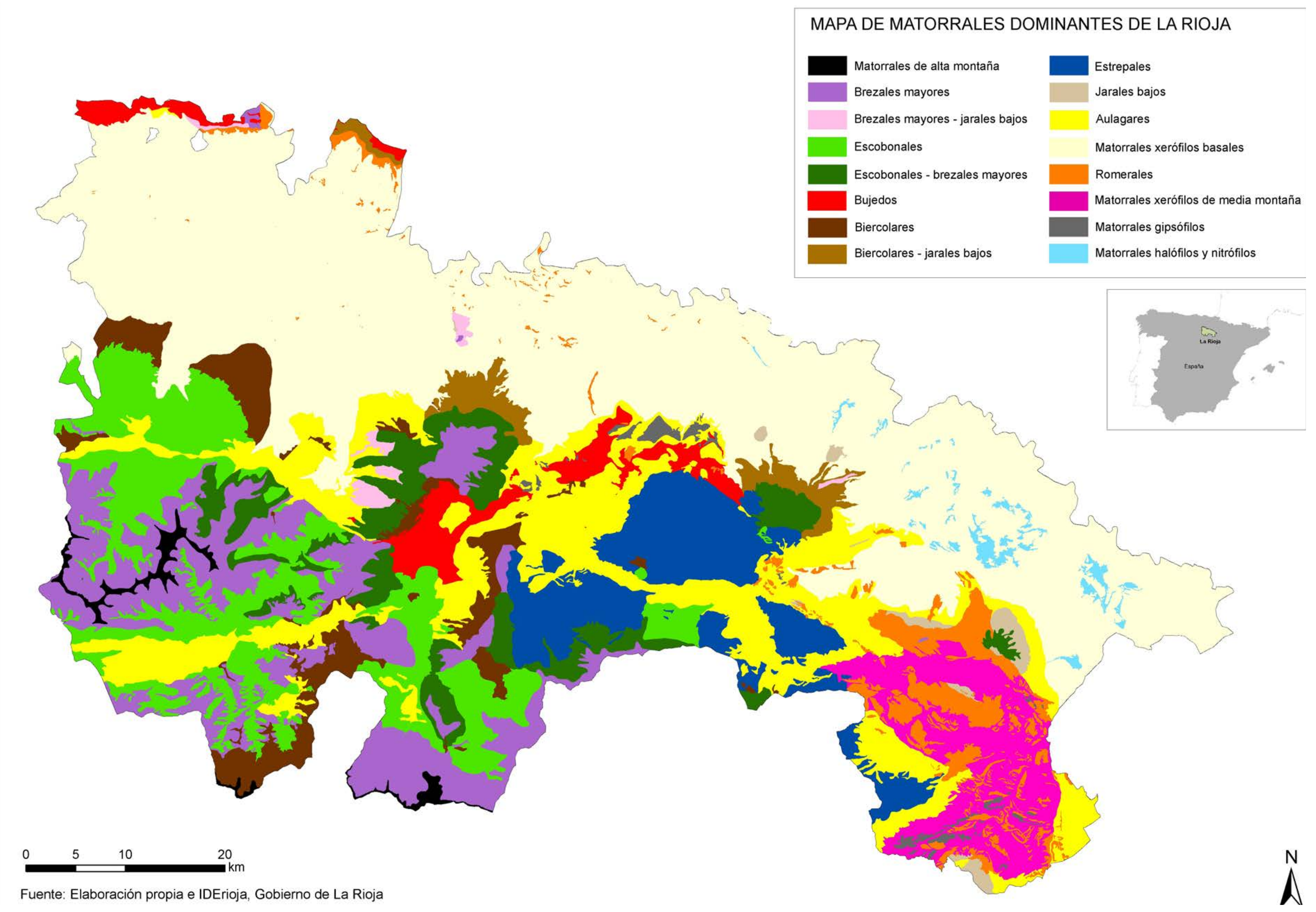

Figura 1: Mapa de Matorrales dominantes de La Rioja. Distribución superficial de las áreas asignables a cada dominio

Figure 1: Map of Dominant Scrub Communities in La Rioja. Distribution of areas allocated to each domain. 
Tabla 3. Correspondencias entre los tipos considerados en la cartografía de matorrales de La Rioja (2018) con los pisos bioclimáticos, los tipos climático-estructurales y las cabeceras teóricas de los complejos evolutivos en los que se insertan.

Table 3. Correspondences among Types considered in the Map of Scrub Communities of La Rioja (2018), Bioclimatic Levels, Structural-Climatic Types of Vegetation and Theoretical Top Plant Covers in the evolutive complexes they are inserted in.

\begin{tabular}{|c|c|c|c|c|c|}
\hline Piso & Ámbito & \multicolumn{2}{|c|}{ Tipo Climático-Estructural } & Cabecera de complejo evolutivo & Tipos de matorral \\
\hline 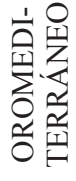 & $\begin{array}{l}\text { Alta montaña. } \\
\text { Sierras de } \\
\text { Demanda, Urbión y } \\
\text { Cebollera }\end{array}$ & \multicolumn{2}{|c|}{$\begin{array}{l}\text { Tipo suprasílvico (Alta Montaña, A) y de } \\
\text { la franja superior del Tipo de Coníferas } \\
\text { orófilas o asimilable a Taigá }(\mathrm{T})\end{array}$} & $\begin{array}{l}\text { Matorrales mixtos de alta montaña } \\
\text { Pinus sylvestris (no en espesura) con } \\
\text { presencia relictual de Pinus uncinata }\end{array}$ & Matorrales de alta montaña \\
\hline \multirow{5}{*}{ 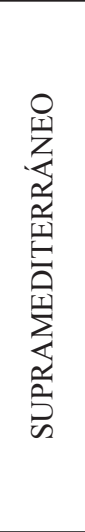 } & \multirow[t]{5}{*}{$\begin{array}{c}\text { Sierras Occidentales } \\
\text { (Alto Oja, Alto Najerilla, } \\
\text { Alto Iregua) }\end{array}$} & \multirow{5}{*}{\multicolumn{2}{|c|}{$\begin{array}{l}\text { Matorrales mesófilos y submesófilos (a.v. } \\
\text { subxerófilos) de los Tipos sílvicos de } \\
\text { Coníferas orófilas (T), Caducifolio (C) y, en } \\
\text { menor medida, Subesclerófilo (S) + húmedo }\end{array}$}} & \multirow{5}{*}{$\begin{array}{c}\text { Pinares albares (Pinus sylvestris) } \\
\text { Hayedos (Fagus sylvatica) } \\
\text { Masas mezcladas de Pinus sylvestris y } \\
\text { Fagus sylvatica } \\
\text { Hayedos (Fagus sylvatica) con inclusiones } \\
\text { de melojares (Quercus pyrenaica) } \\
\text { Bosques mixtos de caducifolios y } \\
\text { subesclerófilos } \\
\text { Robledales mixtos o en mosaico } \\
\text { (Q. pyrenaica, Q. faginea) } \\
\text { (Melojares/rebollares de Quercus } \\
\text { pyrenaica) }\end{array}$} & $\begin{array}{c}\text { Brezales mayores } \\
\text { (variante mesófila de alta y media montaña, } \\
\text { dominada por Erica australis y presencia } \\
\text { significativa de Erica arborea) }\end{array}$ \\
\hline & & & & & $\begin{array}{l}\text { Biercolares } \\
\text { (variante mesófila, excepcionalmente } \\
\text { subxerófila) }\end{array}$ \\
\hline & & & & & $\begin{array}{c}\text { Escobonales-brezales mayores } \\
\text { (variante mesófila, de montaña, con Erica } \\
\text { arborea y, ocasionalmente, Erica australis) }\end{array}$ \\
\hline & & & & & $\begin{array}{l}\text { Escobonales } \\
\text { (variante mesófila) }\end{array}$ \\
\hline & & & & & Estrepales \\
\hline \multirow{6}{*}{ 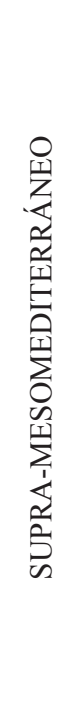 } & \multirow{6}{*}{$\begin{array}{l}\text { Piedemontes del } \\
\text { contacto Sierra/Valle. } \\
\text { Cuenca del Alhama, } \\
\text { Montes Obarenes-Sierra } \\
\text { de Toloño }\end{array}$} & \multirow[b]{2}{*}{ Caducifolio } & \multirow[b]{2}{*}{ Subesclerófilo } & \multirow{6}{*}{$\begin{array}{l}\text { Robledales mixtos o en mosaico } \\
\text { (Q. pyrenaica, Q. faginea) } \\
\text { Melojares/rebollares de Quercus pyrenaica } \\
\text { Robledales de } Q \text {. faginea/Q. gr. humilis } \\
\text { (Hayedos (Fagus sylvatica) en umbrías) }\end{array}$} & $\begin{array}{l}\text { Brezales mayores } \\
\text { (variante submesófila y subxerófila, de media } \\
\text { montaña y de piedemonte, con predominio de } \\
\text { Erica arborea y, localmente, de E. scoparia) }\end{array}$ \\
\hline & & & & & $\begin{array}{c}\text { Escobonales-brezales mayores } \\
\text { (variante submesófila o subxerófila, de } \\
\text { montaña y de piedemonte, con Erica } \\
\text { scoparia en piedemonte y, en menor medida, } \\
\text { Erica arborea) }\end{array}$ \\
\hline & & \multirow{4}{*}{\multicolumn{2}{|c|}{$\begin{array}{l}\text { Matorrales submesófilos o subxerófilos del } \\
\text { Tipo Subesclerófilo }\end{array}$}} & & Bujedos \\
\hline & & & & & $\begin{array}{l}\text { Escobonales } \\
\text { (variante de zonas de transición, } \\
\text { submesófilos o subxerófilos) }\end{array}$ \\
\hline & & & & & $\begin{array}{c}\text { Brezales mayores-Jarales bajos } \\
\text { (variante de piedemonte con Erica scoparia, } \\
\text { Cistus albidus y, en menor medida, Erica } \\
\text { arborea) }\end{array}$ \\
\hline & & & & & Biercolares-Jarales bajos \\
\hline
\end{tabular}




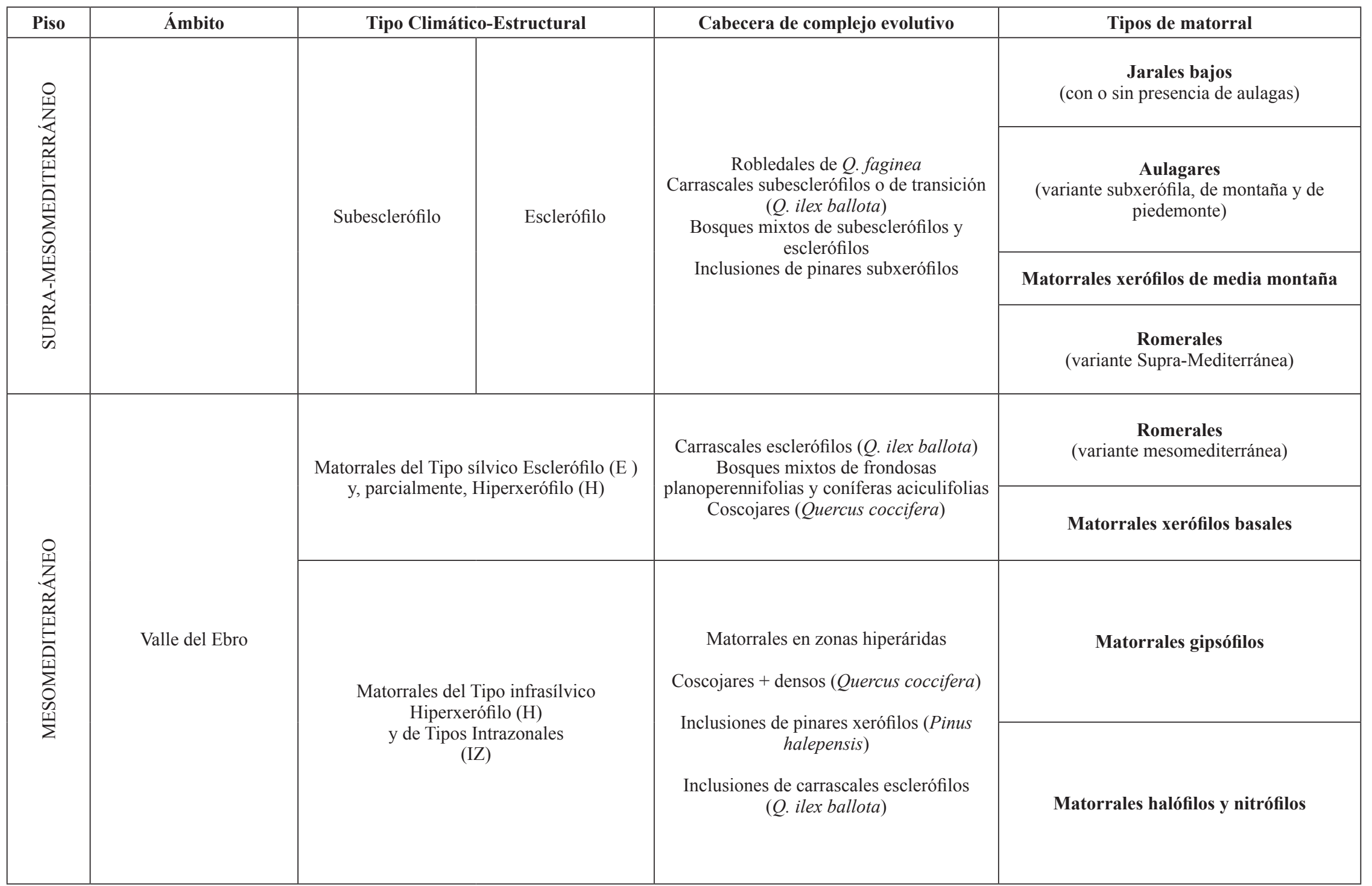


jándose también los grandes ámbitos de los principales pisos bioclimáticos existentes en La Rioja: Oromediterráneo, Supramediterráneo y Mesomediterráneo (RivasMartínez, 1987, 2007; Fernández Aldana, 2015).

\section{a) PISO OROMEDITERRÁNEO (CUMBRES DE LAS SIERRAS IBÉRICAS)}

El ámbito de este piso, con precipitaciones elevadas por encima de los $1.000 \mathrm{~mm}$ anuales, está restringido a las zonas de cumbres por encima de los 1.800-1.900 m de las sierras de La Demanda, Urbión y Cebollera. Se trata de estaciones con climas húmedos de inviernos acusadamente fríos, generalmente de continentalidad marcada, y, en consecuencia, un parón vegetativo con un período de actividad relativamente corto y posibilidad de heladas tardías. Los veranos son relativamente breves, frescos, y sin déficit apreciable de agua disponible.

Las cubiertas de matorral pertenecen al conjunto de las características de alta montaña y de la zona de coníferas orófilas, siendo asignables a los ámbitos potenciales de los dominios correspondientes a los Tipos estructurales zonales de Alta Montaña (Tipo A) y, secundariamente, de formaciones arboladas de coníferas aciculifolias microtermas, higrófilas o subhigrófilas a subxerófilas, (Tipo $\mathrm{T}$ o de Coníferas aciculifolias orófilas microtermas). Son bosques fisonómica y ecológicamente asimilables a la taiga noreuropea donde la especie principal en La Rioja es Pinus sylvestris (y localizada en el entorno del Pico del Castillo de Vinuesa, Pinus uncinata). Dentro de este piso tan sólo se ha definido un único tipo de matorral dominante, los matorrales de alta montaña.

\section{Matorrales de alta montaña}

Se ha definido con esta denominación la agrupación formada por varios tipos de matorral y compuesta, principalmente, por el biércol, Calluna vulgaris, el enebro rastrero, Juniperus communis ssp. alpina, y, en menor medi$\mathrm{da}$, el piorno, Cytisus oromediterraneus, preferentemente en las solanas. Los matorrales orófilos son agrupaciones vegetales tradicionalmente sometidas a incendios recurrentes para la regeneración de los pastos de la alta montaña que favorecen y estabilizan al piorno y al propio biércol, y reducen o, incluso, pueden llegar a suprimir la presencia del enebro rastrero.

$\mathrm{Su}$ distribución coincide con cumbres, divisorias, laderas y cantiles expuestos, en relieves convexos no encharcables, y también próximos a canchales, pedregales, morrenas etc., sobre suelos de escaso desarrollo. Este complejo de matorrales ocupa la porción más elevada del Sistema Ibérico riojano a partir de los 1.800-1.900 (Figura 2), distribuyéndose en los siguientes núcleos:

- Sierra de La Demanda (2.271 m), en donde son especialmente abundantes en el tramo San LorenzoPancrudos y zonas circundantes.
- Sierra de Urbión (2.228 m), distribuidos por las cabeceras de los ríos Portilla, Urbión y Ormazal, con una superficie actual más reducida a causa de la histórica presión ganadera.

- Sierra de Cebollera (2.142 m), con abundancia en toda la línea de cumbres, especialmente en La Mesa y cabeceras de los ríos Iregua y Lumbreras, y llegando hasta las cercanías del puerto de Piqueras.

\section{b) PISO SUPRAMEDITERRÁNEO (SIERRAS IBÉRICAS)}

Dentro del piso Supramediterráneo pueden distinguirse dos subzonas con sendos gradientes térmicos y pluviométricos en sentido oeste-este:

- b.1. Sierras occidentales, con altitudes elevadas y medias, de tendencia oceánica o suboceánica, en parte continental, y con temperaturas frías más extremas.

- b.2. Sierras orientales de altitudes medias y con tendencia submediterránea, es decir, menores precipitaciones y temperaturas más elevadas.

\section{b.1) SIERRAS OCCIDENTALES}

Forma parte de este ámbito territorial el conjunto montañoso de las sierras de La Demanda, Urbión y Cebollera, área que abarca, en términos generales, las cuencas altas y medias del Oja y Najerilla, la cuenca alta y parte de la media del Iregua, y la cuenca alta del Leza, junto con el enclave montañoso de la Sierra de La Hez (Cabimonteros, $1.388 \mathrm{~m}$ ). El ombroclima varía entre el húmedo inferior de las sierras suboceánicas (cuenca del Oja y cuenca media del Najerilla) y el subhúmedo superior del resto (cuenca alta del Najerilla y media y alta del Iregua).

Los matorrales de este núcleo territorial, mesófilos y submesófilos (a veces subxerófilos), se corresponden con el ámbito potencial de los bosques planocaducifolios mesófilos (Tipo C) que, a menudo, aparece entremezclado con las coníferas de montaña (Tipo T) o repartiéndose las distintas exposiciones. Está relacionado con variantes climáticas de invierno frío o templado-frío que imponen el reposo fisiológico invernal característico de los caducifolios, de entre 5 a 8 meses, y un periodo vegetativo medio, mientras que el verano varía de templado a templado-cálido siendo más cálido y húmedo, sin déficit hídrico.

Los matorrales dominantes se corresponden con hayedos en el sector más húmedo y con hayedo-robledales (umbría/solana) hacia el este por disminución de las precipitaciones. Los matorrales dominantes característicos de este ámbito bioclimático son los siguientes: brezales mayores, escobonales-brezales mayores, escobonales y biercolares.

En los tres primeros tipos se presentan variantes, de mayor o menor higrofilia, que se extienden desde el Supramediterráneo hasta los espacios de transición con el 


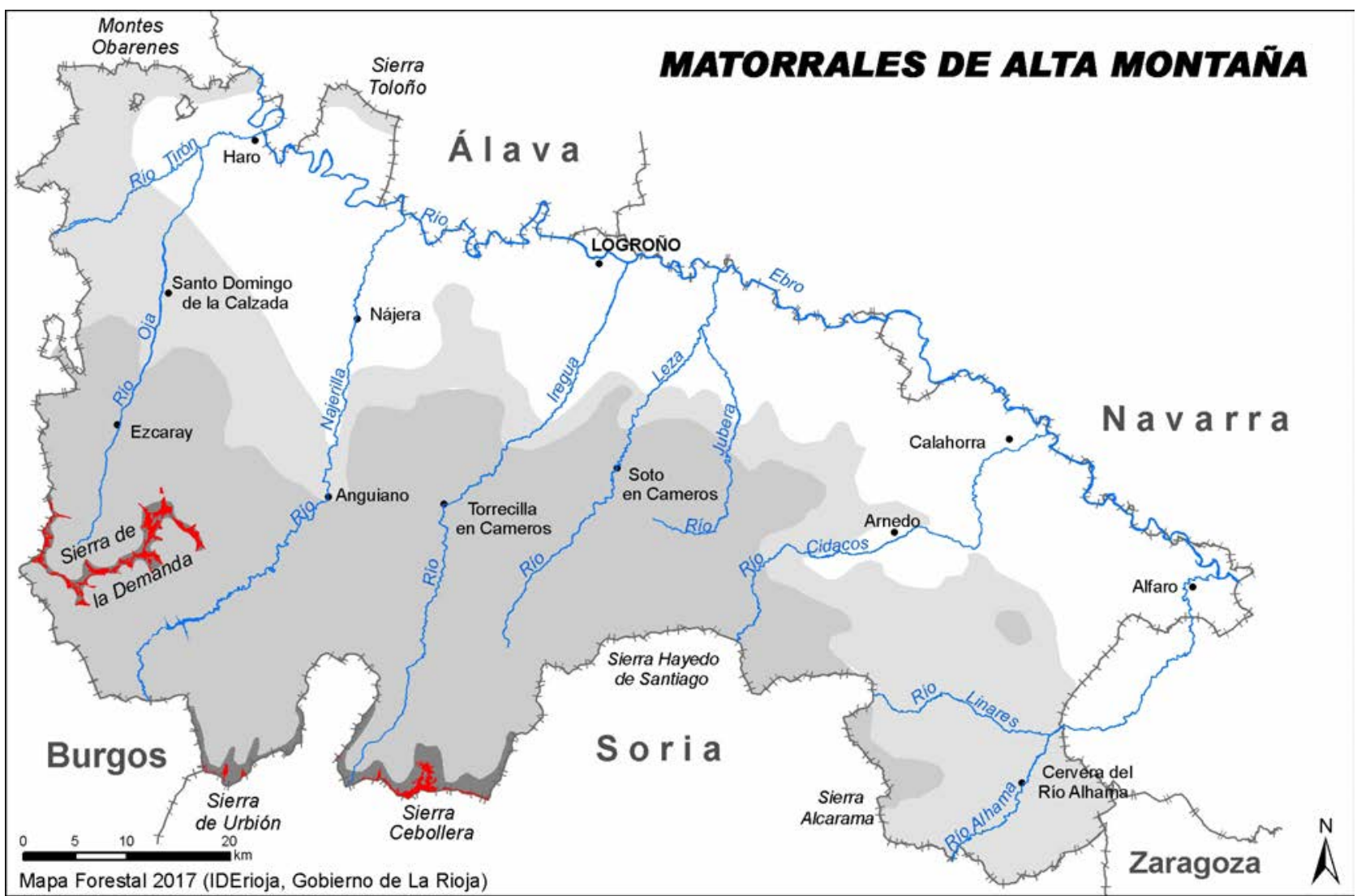

Figura 2: Distribución de los matorrales de alta montaña en La Rioja.

Figure 2: Distribution Map of High Mountain scrub communities in La Rioja.

piso Mesomediterráneo. También los biercolares descienden a zonas de transición entre la Sierra y el Valle por los piedemontes más húmedos de la cuenca del Oja.

Así, en los enclaves de clima local más húmedo se encontrarían: brezales mayores de alta y media montaña con Erica australis y/o Erica arborea, escobonales mesófilos y escobonales-brezales mayores con Erica arborea en media montaña y, en menor medida, Erica australis. Y en las zonas comparativamente más secas: brezales mayores de media montaña y piedemonte con Erica arborea y/o Erica scoparia, escobonales submesófilos o subxerófilos en franjas de transición y escobonales-brezales mayores con Erica arborea y/o Erica scoparia en piedemonte.

\section{Brezales mayores}

Se componen de una o varias de las especies de brezos de mayor talla: Erica australis, Erica arborea y Erica scoparia. La especie Erica australis es comparativamente más xerófila que Erica arborea y se instala con preferencia en las zonas de cumbre y en las laderas expuestas a vientos desecantes o a insolación directa, comportándose en La Rioja como especie orófila asociada a climas locales más continentales. Por el contrario, el brezo blanco,
Erica arborea, medra con preferencia en los mosaicos sobre las laderas más umbrosas y allí donde es frecuente la presencia de escobas (Genista, Cytisus), formando la agrupación escobonales-brezales mayores que desciende a rangos inferiores de altitud. Es significativa la presencia de brezales de Erica scoparia en la Sierra de Moncalvillo $\mathrm{y}$ en los Montes Obarenes, representando una variante más termo-higrófila.

En el área de distribución de este tipo de matorral (Figura 3) se incluyen conjuntamente las dos variantes referidas a sus componentes principales y relacionadas, sobre todo, con franjas altitudinales:

- Brezales mayores de alta y media montaña con Erica australis y/o Erica arborea. Suben casi hasta la línea de cumbres en las sierras más elevadas con cotas de 1.800-1.900 $\mathrm{m} \mathrm{y}$, de hecho, penetran en el matorral de alta montaña del que, a menudo, forman parte. Estos brezales mayores se localizan en las siguientes áreas:

- Sierra de la Demanda y sus estribaciones en los valles del Oja, Cárdenas, Tobía y Valvanera, en el intervalo entre 1.200 y $1.800 \mathrm{~m}$, constituyendo el mayor núcleo de su población.

- Sierra de Urbión: en las laderas del pico Cerezales $(1.861 \mathrm{~m})$, en los interfluvios de los ríos Nei- 


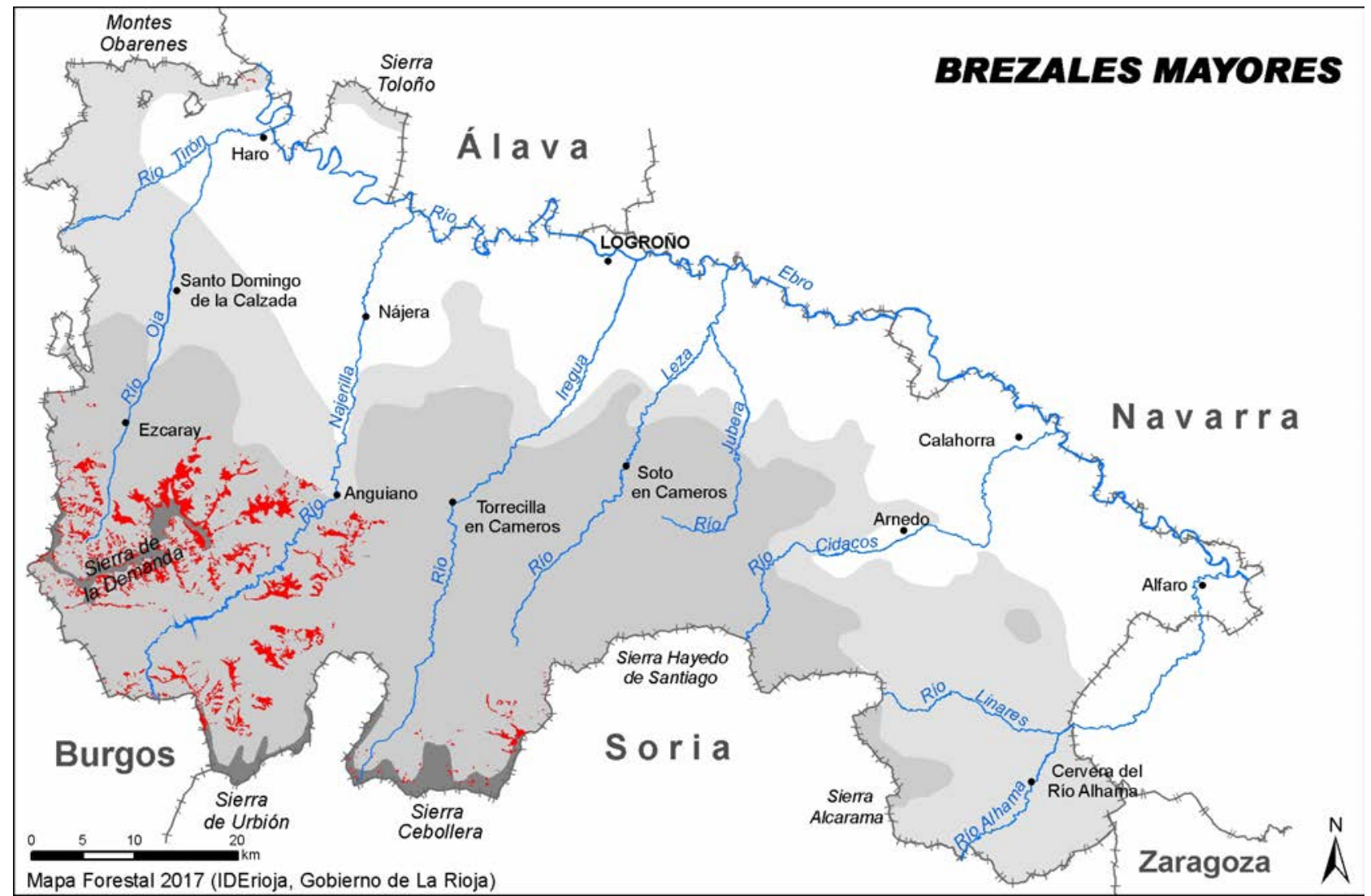

Figura 3: Distribución de los brezales mayores en La Rioja.

Figure 3: Distribution Map of High Heathlands (Erica) in La Rioja.

la, Portilla, Urbión y Ormazal. Dentro de este grupo también puede incluirse la margen derecha del río Najerilla desde la umbría de Cerro Urbaña $(1.671 \mathrm{~m})$ hasta Anguiano, variando entre los $1.100 \mathrm{y}$ los $1.650 \mathrm{~m}$.

- Sierra de Cebollera, donde los brezales, escasos por la gran presencia de bosques, se distribuyen por las zonas altas de Hoyos de Iregua hasta el puerto de Piqueras y se prolongan hasta la línea de cumbres de la cabecera del Leza y del Hayedo de Santiago. También ocupan en esta zona las laderas de Mojón Alto $(1.768 \mathrm{~m})$ entre Ortigosa y Villoslada de Cameros.

- Cuenca media del Iregua, ocupando los escasos claros que dejan los bosques dominantes en los interfluvios del Najerilla-Iregua (Sierra de Moncalvillo), y del Iregua-Leza (El Horquín-puerto de La Rasa), entre los 1.400 y los $1.500 \mathrm{~m}$.

- Brezales mayores de media montaña y piedemonte con Erica arborea y/o Erica scoparia. A falta de profundizar en la autoecología de Erica scoparia en La Rioja, se puede afirmar, sin embargo, que tiene una ubicación definida y con cierta extensión en los Montes Obarenes, en torno a los 550-600 m, y en el piedemonte de la Sierra de Moncalvillo dentro de la agrupación de brezales mayores-jarales bajos.
También aparecen, ya en el piso Mesomediterráneo, en enclaves o en elevaciones menores y sus glacis dentro del territorio del Valle del Ebro: carrascal de Cidamón, dehesa de Navarrete, monte La Estrella de Ausejo, carrascales del piedemonte de Sierra de La Hez, monte de Gatur y Sierra de Yerga entre Autol y Alfaro.

\section{Escobonales-brezales mayores}

Esta agrupación mixta se extiende, fragmentadamente, en las zonas de contacto entre los brezales de rangos altitudinales más elevados y las zonas de media montaña. También aparece en laderas de umbría, en donde predomina Erica arborea, que es el brezo mayoritario y representativo de esta agrupación junto con las leguminosas retamoideas propias de los escobonales a las que sustituye en amplias superficies de transición.

$\mathrm{Su}$ distribución (Figura 4) es muy semejante a la de los escobonales en las cuencas medias del Oja, Najerilla e Iregua, apareciendo con mayor entidad en las laderas de la Sierra de Moncalvillo. En las cuencas de clima más suboceánico, Oja y Najerilla, descienden desde 1.500-1.600 $\mathrm{m}$ hasta los $850-950 \mathrm{~m}$. En la del Iregua se ubican entre los 1.550-1.650 m y los $1.150 \mathrm{~m}$, aunque a veces llegan a bajar hasta los 850-900 m en el piedemonte de Moncalvi- 


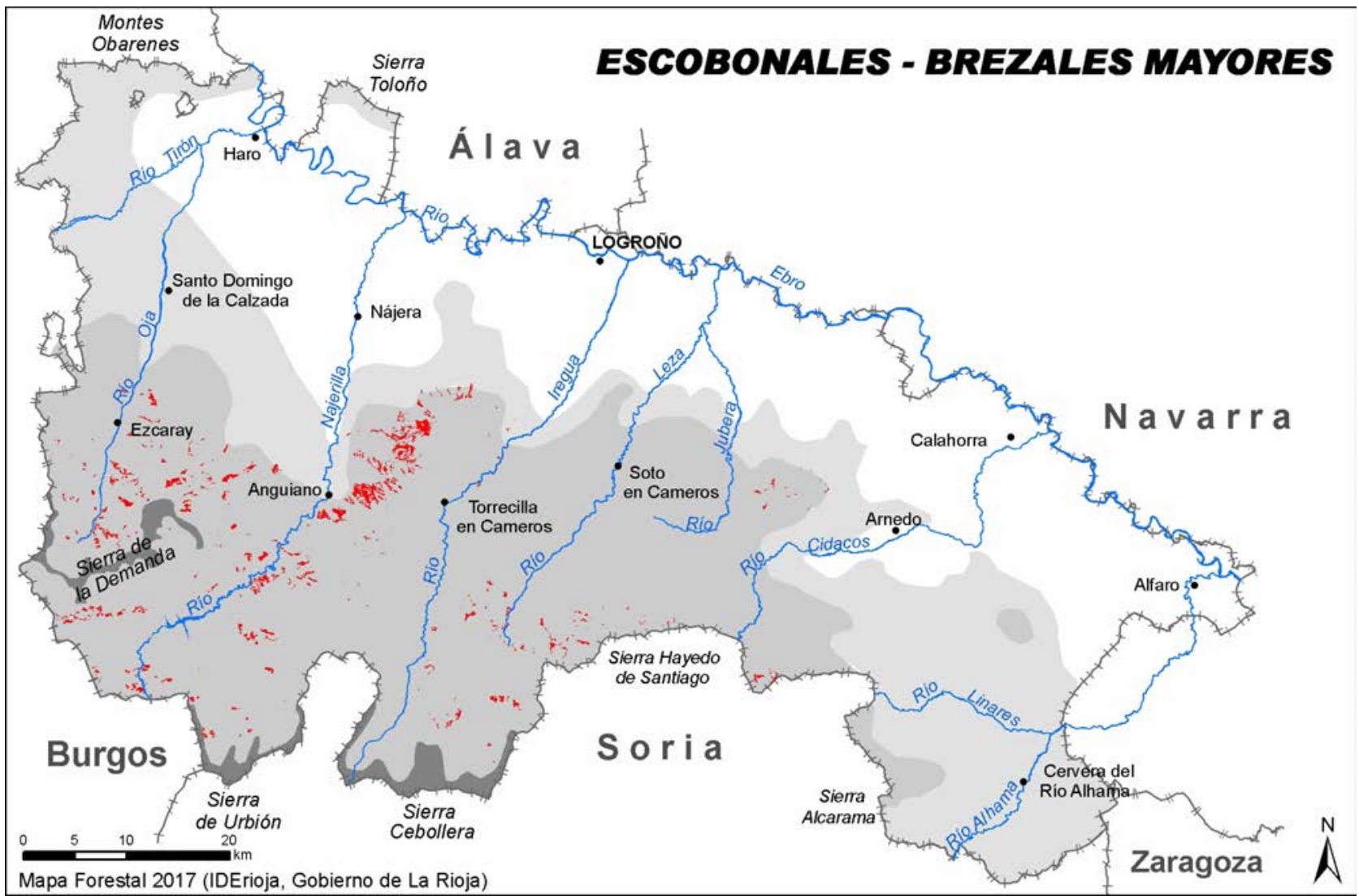

Figura 4: Distribución de los escobonales-brezales mayores en La Rioja.

Figure 4: Distribution Map of Broom-like Scrubs (Genista, Cytisus) - High Heathlands (Erica) in La Rioja.

llo y, de forma más localizada, hasta los 750 m (Castañares de las Cuevas).

En la cuenca alta del Leza ocupa, con escasa superficie, la práctica totalidad del dominio potencial de los escobonales, entre 1.200 y $1.500 \mathrm{~m}$. En la del Cidacos, de forma similar, se extiende entre los 1.450 y los $1.150 \mathrm{~m}$, como en el caso del Hayedo de Poyales. Los escobonales-brezales mayores aparecen en enclaves más húmedos dentro de ámbitos de clima más mediterráneo, caso de Sierra de La Hez entre los 1.250-1.300 $\mathrm{m}$ de la cumbre y los 900-1.000 $\mathrm{m}$ del piedemonte, y en donde se confunden con los escobonales. Hacia el este llegan, de forma puntual por la intercalación de montes arbolados, hasta la Sierra de Yerga $(1.101 \mathrm{~m})$.

\section{Escobonales}

Dentro de este tipo genérico pueden encontrarse escobonales formados por Genista florida y/o por Cytisus scoparius. La especie más característica es el escobón o escoba blanca, Genista florida, frecuente en comarcas de clima más húmedo o subocéanico aunque también coloniza laderas de fuertes pendientes en orientaciones soleadas (Najerilla). En la variante de tipo submediterráneo de transición suele ser más claramente dominante la escoba negra, Cytisus scoparius, de carácter algo más xerófilo y ligada a la ocurrencia y reiteración de incendios; también es, a veces, el único dominante en subpisos de bosques mesófilos, como los melojares de Quercus pyrenaica.

Ocupan principalmente (Figura 5) las montañas medias de las cuencas de los ríos Oja, Najerilla e Iregua, alcanzando en su límite superior los 1.500-1600 m; en las solanas esta cota se eleva hasta alcanzar los 1.700-1.800 m, como sucede en el río Portilla (Sierra de Urbión) o en la cuenca del Iregua (Mojón Alto). En su contacto con el Valle del Ebro descienden hasta los $700 \mathrm{~m}$ en los piedemontes del Oja (Montes de Ayago) o del Najerilla, y hasta los $850 \mathrm{~m}$ en los del Iregua.

Los escobonales tienen escasa presencia en la cuenca del Leza, situándose en las proximidades de las divisorias y cumbres (1.450-1.500 m) y en donde su espacio potencial parece haber sido ocupado por los estrepales (Cistus laurifolius) en un proceso de degradación o pérdida de nivel evolutivo en las cubiertas vegetales; bajan hasta los $1.250 \mathrm{~m}$ en las laderas del pico Atalaya (dehesa de Hornillos), asimismo en mezcla con estrepales.

También alcanzan la cuenca del río Manzanares, tributario del Cidacos, en franjas altitudinales que, desde los 1.450-1.400 m, descienden hasta los $850 \mathrm{~m}$, al igual que sucede en el Hayedo de Poyales y en los enclaves de Sierra de La Hez, en donde bajan hasta los 900-1.000 metros. Los escobonales desaparecen en la cuenca del Alhama, dejando paso sobre suelos silíceos a los estrepales. 


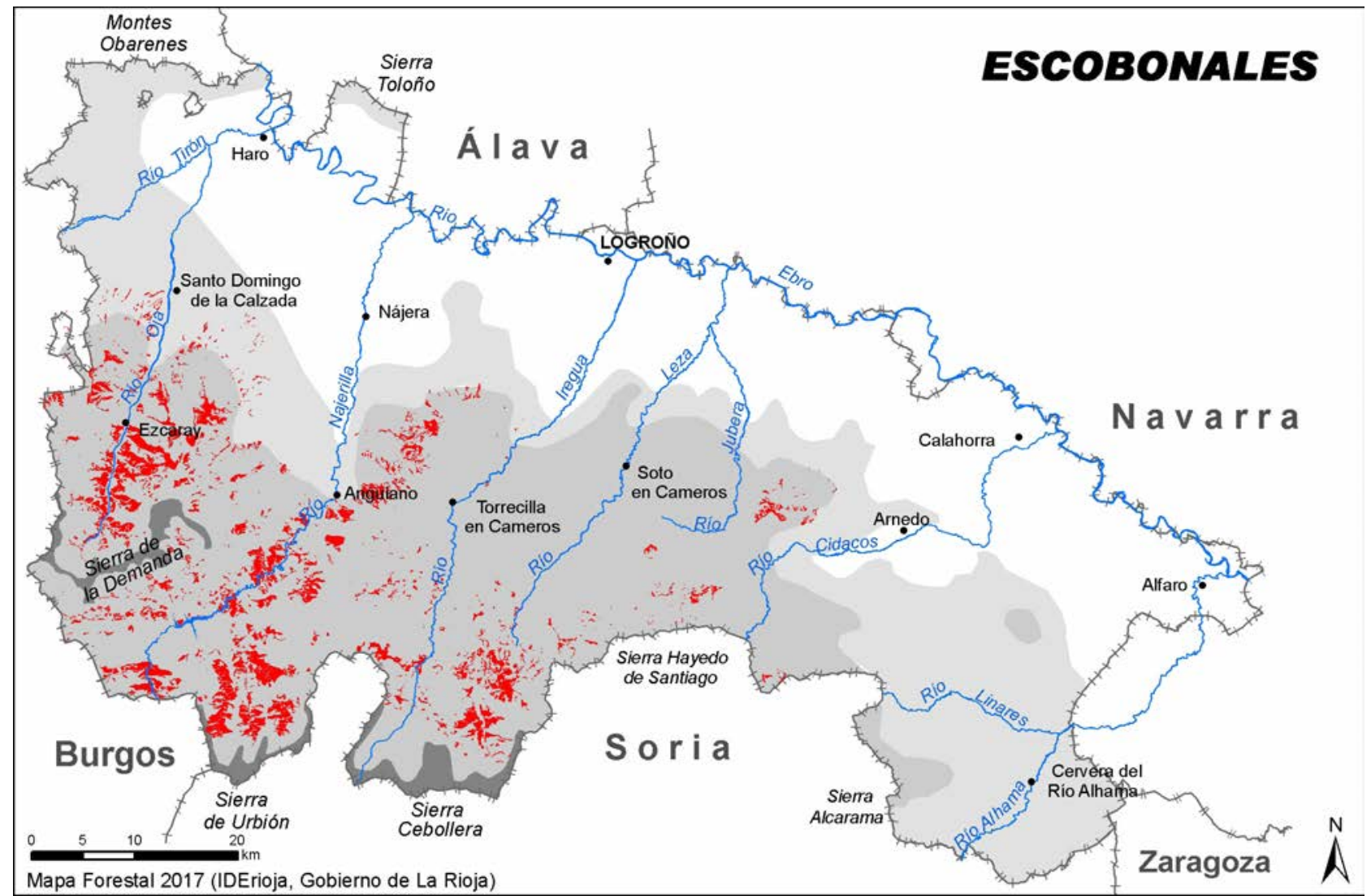

Figura 5: Distribución de los escobonales en La Rioja.

Figure 5: Distribution Map of Broom-like Scrubs (Genista, Cytisus) in La Rioja.

\section{Biercolares}

Son agrupaciones dominadas por brezos de tallas menores o biércoles (Erica vagans, Erica cinerea y la brecina Calluna vulgaris). Se trata de matorrales bajos ciertamente ubicuos que, a menudo, entran en contacto y se mezclan con los brezales mayores y los escobonales, representando niveles evolutivos inferiores a los de estos últimos tipos y son resultado de una estabilización derivada principalmente de la actividad ganadera.

Estos matorrales se asientan, en su mayoría, sobre suelos silíceos o calizos descarbonatados y tienen una gran amplitud altitudinal (Figura 6), pudiendo distinguirse dos ámbitos territoriales principales:

- Piedemontes del contacto Sierra/Valle, cuencas del Oja y del Najerilla, en la transición entre los pisos Supra y Mesomediterráneo (Montes de Ayago y Fonfría), generalmente con presencia de escobonales. En estas zonas ascienden hasta los $900 \mathrm{~m}, \mathrm{y}$, a partir de esa cota, ceden el predominio a los escobonales; por el contrario, en su límite inferior, bajan hasta los 600$700 \mathrm{~m}$, y es posible que pudieran hacerlo aún más allí donde los cultivos agrícolas lo impiden.

- Montañas medias y altas en zonas de cumbres y cordales, generalmente pastoreadas, en las cuencas del
Oja (Valgañón), del Najerilla (sierras de Urbión y de Castejón) y del lregua (Serradero, La Pineda y el interfluvio Iregua-Leza, de El Horquín a Ribavellosa), con diversos enclaves asociados a las zonas más elevadas, como en el caso de La Atalaya (cuenca del Leza) y del Hayedo de Poyales (Cidacos).

En estas zonas de montaña ocupan diversos rangos de altitud, desde los $1.250 \mathrm{~m}$ en el Oja hasta los casi $1.900 \mathrm{~m}$ en las cumbres de la Sierra de Urbión, pasando por altitudes intermedias entre los 1.300 y los $1.400 \mathrm{~m}$ (Serradero, Almarza, La Atalaya, Hayedo de Poyales). En la cuenca del Alto Najerilla es donde estos matorrales tienen una mayor extensión en mezcla con pastos herbáceos extensivos, variando entre los $1.450 \mathrm{~m}$ del puerto de Canto Hincado, en Brieva de Cameros, hasta las elevadas cumbres de la Sierra de Urbión $(2.228 \mathrm{~m})$.

\section{b.2) SIERRAS ORIENTALES}

Estas sierras, de carácter submediterráneo, se extienden por las montañas que abarcan, fundamentalmente, las cuencas del Leza y su afluente el Jubera, del Cidacos y del Alhama, junto con el enclave más húmedo de las cumbres de la Sierra de Yerga. Su posición en el extremo 


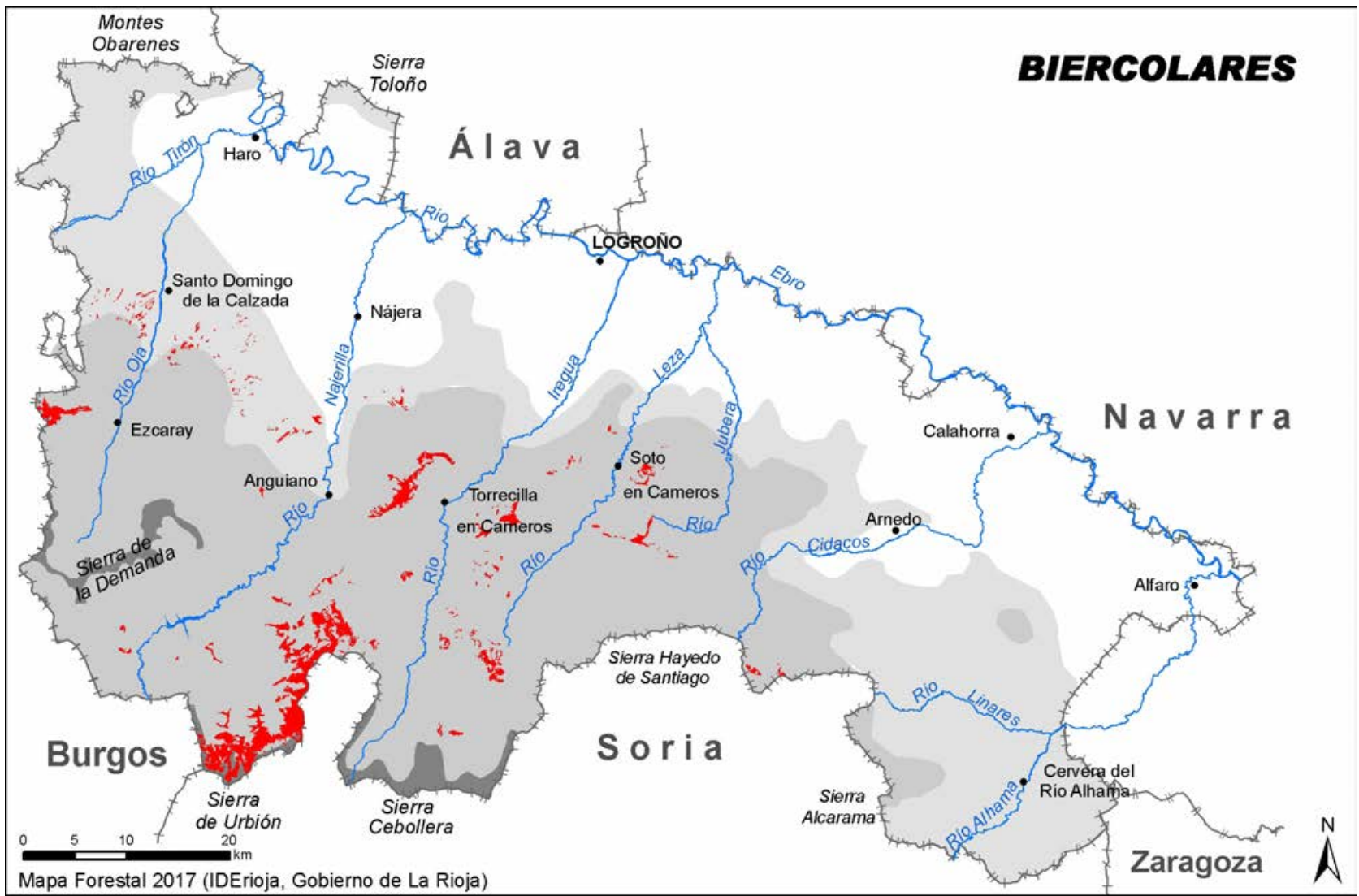

Figura 6: Distribución de los biercolares en La Rioja.

Figure 6: Distribution Map of Low Heathlands (Erica, Calluna) in La Rioja.

oriental del sector central riojano implica la disminución de las precipitaciones y un cambio significativo en los tipos de matorrales dominantes existentes.

Se corresponden con el ámbito potencial de los bosques submediterráneos, fundamentalmente planocaducifolios en su variante marcescentifolia, aunque ya subesclerófilos (Tipo S de Ruiz de la Torre, 1990), de hojas adaptadas para evitar la desecación por transpiración, con alguna representación de especies de hoja caduca o incluso de árboles eurioicos de hoja plana y persistente, como la encina (Quercus ilex ballota).

Este dominio se extiende por altitudes de media montaña, en la franja aproximada de los 800-1.200 m, e incluso en cotas más bajas, con clima de variante submediterránea, esto es, con sequía estival atenuada por la altitud o la exposición, marcando un período subseco, y con inviernos fríos o templado-fríos. Por lo tanto, los matorrales dominantes en este sector están asociados a bosques subesclerófilos de robles (rebollares y quejigares, Quercus pyrenaica, $Q$. $g r$. faginea), con presencia de encinares en las estaciones más cálidas o en los lugares más degradados. En las umbrías más protegidas se insertan hayedos de carácter marginal.

Los matorrales dominantes en estas sierras, de tipo general submediterráneo, son los estrepales de Cistus laurifolius, a los que acompañan los aulagares y, también, los bujedos, que penetran desde las zonas de transición.

\section{Estrepales}

Esta agrupación monoespecífica está dominada por la estrepa o jara, Cistus laurifolius, especie fuertemente asociada a los incendios reiterados de origen ganadero destinados al rebrote de los pastos. Se trata de un tipo subxerófilo o xerófilo y heliófilo, que tolera tanto fríos intensos como sequía, siendo un indicador de los suelos pobres en materia orgánica que dominan en los sustratos silíceos del territorio de las sierras orientales. Por el contrario, en el dominio de los melojares del piso Supramediterráneo, con ombroclima subhúmedo, deja paso a los brezales mayores y a los escobonales. Hay una variante calcícola del estrepal, en mezcla con Genista scorpius y lasto-timoaliagares, que está profusamente extendida y con frecuente presencia de espinos caducifolios dispersos.

Los estrepales se extienden por las cuencas media y alta del Leza y del Jubera, la cuenca media del Cidacos y por la cuenca del Alhama (Sierra de Alcarama) (Figura 7). Este tipo de matorral tiene como cotas superiores: $1.350-1.400 \mathrm{~m}$ en la cuenca alta del Leza $(1.450 \mathrm{~m}$ en el entorno de la Atalaya) y 1.250-1.300 m en el Cidacos; en el caso de la cuenca del Alhama su límite altitudinal varía entre los $1.300 \mathrm{~m}$ en la cuenca del Linares (CornagoMuro de Aguas) y los $1.450 \mathrm{~m}$ en la Sierra de Alcarama. Las cotas inferiores son también variables: bajan hasta los 


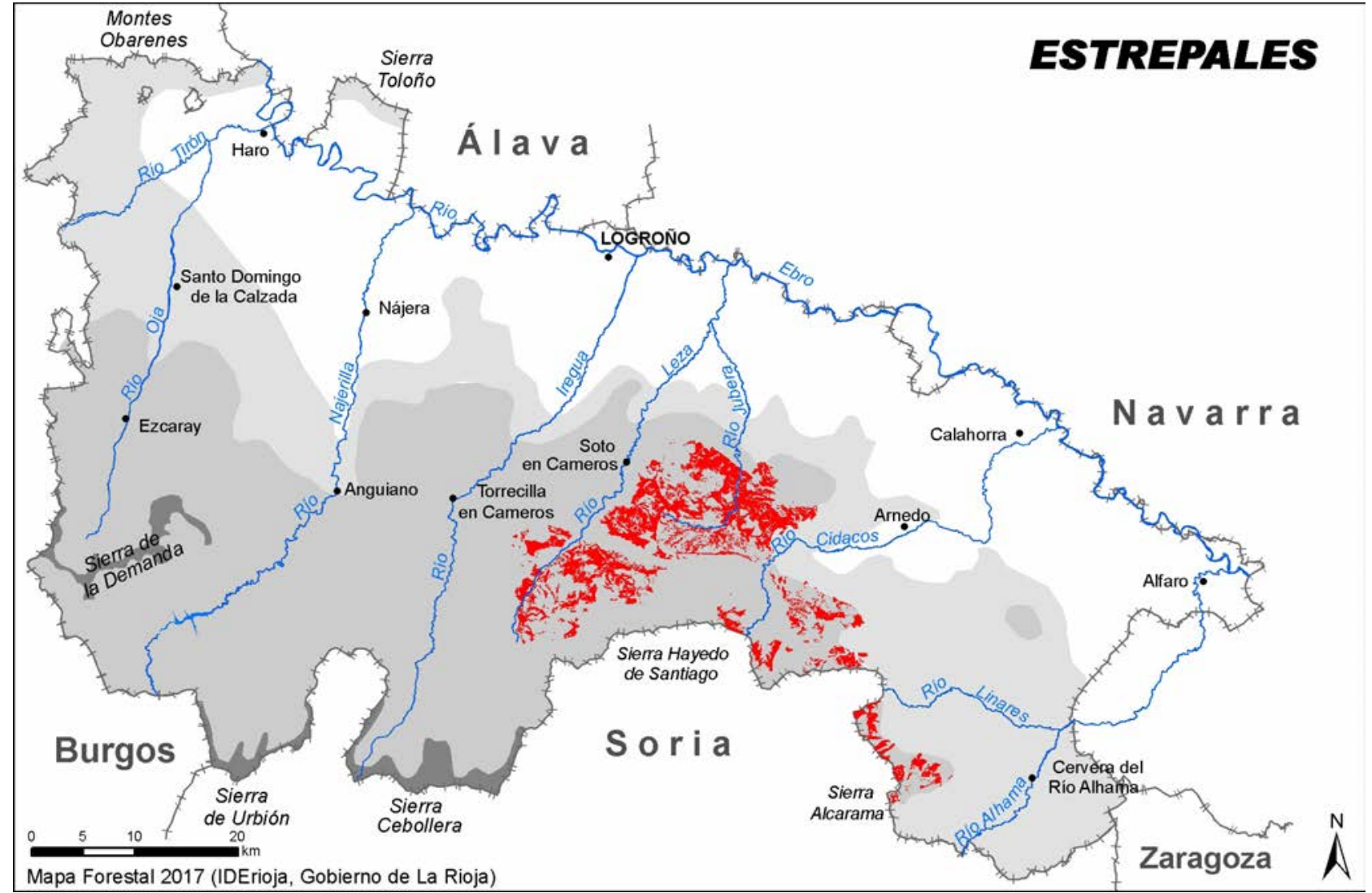

Figura 7: Distribución de los estrepales en La Rioja.

Figure 7: Distribution Map of Laurel-leaved Rockrose Scrubs (Cistus laurifolius) in La Rioja.

$800 \mathrm{~m}$ en las cuencas del Leza, Jubera y Cidacos y llegan a los $900 \mathrm{~m}$ en la cuenca del Linares, tributario del Alha$\mathrm{ma}$, y a los $1.000 \mathrm{~m}$ en las estribaciones de la Sierra de Alcarama. Penetra puntualmente en las solanas de las cuencas del Najerilla (Valvanera) y del Iregua (Lumbreras, Moncalvillo, Almarza, etc.)

\section{c) TRANSICIÓN ENTRE LOS PISOS SUPRAMEDITERRÁNEO Y MESOMEDITERRÁNEO (PIEDEMONTES Y MONTAÑAS MEDIAS)}

La transición entre los pisos Supra y Mesomediterráneo se extiende por dos ámbitos principales:

- Los piedemontes que establecen el contacto entre las zonas de montaña y el Valle del Ebro, a los que habría que añadir los enclaves de Peñalmonte y Peña Isasa de la cuenca del Cidacos, y los bordes montañosos al norte de La Rioja Alta (Montes Obarenes y Sierra de Toloño).

- Las montañas medias, con menores altitudes en el extremo del gradiente altitudinal oeste-este, que ocupan la cuenca del Alhama y su afluente el río Linares.
Los matorrales más representativos de estas zonas de transición son los siguientes: bujedos, biercolares-jarales bajos, brezales mayores-jarales bajos, jarales bajos, aulagares, romerales y matorrales xerófilos de media montaña.

\section{Bujedos}

En este tipo de matorral la especie principal y predominante es el boj (Buxus sempervirens) que se asienta sobre sustratos calizos, mayoritariamente rocosos. Junto a los bujedos es frecuente que se encuentren especies rupícolas de similar mesología como la sabina, Juniperus phoenicea, además de arbustedos típicamente acompañantes en toda su área de distribución ibérica: guillomares (Amelanchier ovalis) y espinares mixtos o con predominio de alguno de sus componentes, espinos albares (Crataegus monogyna), escaramujos (Rosa sp.) y endrinos (Prunus spinosa), además de arbustos inermes (Cornus sanguinea, Ligustrum vulgare, Viburnum lantana, Euonymus europaeus), con una presencia territorial más residual.

Pueden describirse dos núcleos de distribución principal de los bujedos (Figura 8): 


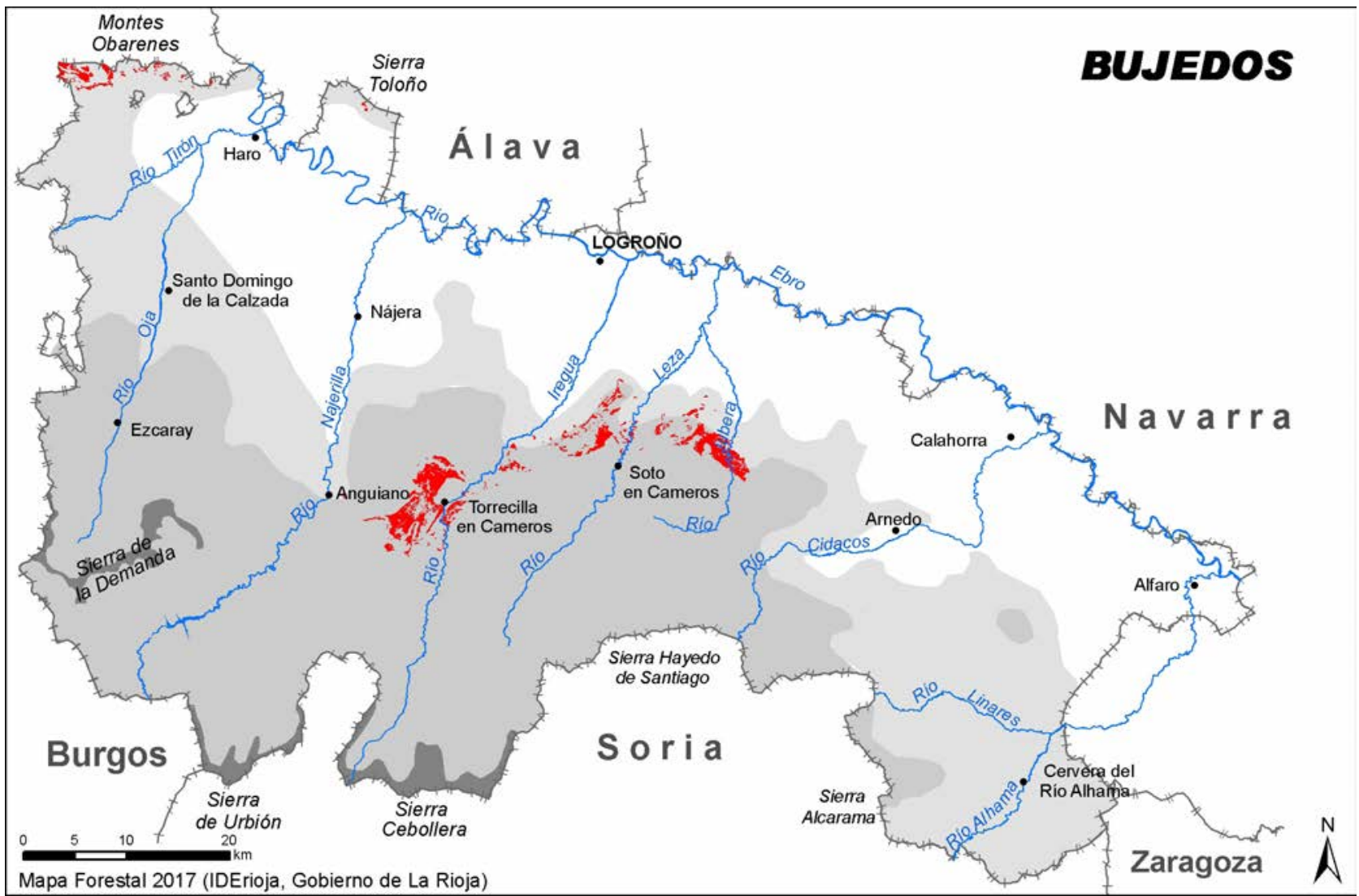

Figura 8: Distribución de los bujedos en La Rioja.

Figure 8: Distribution Map of Boxwood Communities (Buxus sempervirens) in La Rioja.

- Las cuencas medias del Iregua, Leza y Jubera, enlazadas a través de los piedemontes (Monte Laturce y Peña Tejero). Aparece al oeste un enclave en la del Najerilla (Anguiano) y, al este, en la cuenca del Cidacos, un reducido rodal en las faldas de Peña Isasa (Turruncún) a $1.250 \mathrm{~m}$.

En su principal ámbito territorial los bujedos alcanzan $1.400 \mathrm{~m}$ en las cumbres del Serradero, interfluvio entre el Najerilla y el Iregua; $1.250 \mathrm{~m}$ entre el Iregua y el Leza, y hasta $1.100 \mathrm{~m}$ en Peña Tejero, ya en la cuenca del Jubera. En su límite inferior descienden hasta los 700-750 $\mathrm{m}$ en los piedemontes del Iregua, Leza y Jubera.

- Los Montes Obarenes y la Sierra de Toloño. En ambos casos alcanzan la línea de cumbres hasta los $900 \mathrm{~m}$ y los $1.150 \mathrm{~m}$, respectivamente. En su cota más baja llegan hasta los $600 \mathrm{~m}$ en los piedemontes de Obarenes y hasta los $700 \mathrm{~m}$ en Toloño en posiciones de solana.

\section{Biercolares-jarales bajos}

Componen esta agrupación como especies principales una mezcla de biércoles o brezos bajos (Calluna vulgaris, Erica vagans, Erica cinerea) y de estepas bajas o jaguar- zos (Cistus albidus, Cistus salviifolius), a los que acompañan otras especies como Lavandula stoechas y Thymus mastichina.

Estos matorrales se instalan sobre los glacis de la zona montana en transición al Valle del Ebro sobre suelos silíceos o descarbonatados, que favorecen la presencia de amplias zonas de sustratos de reacción ácida. Aparecen dentro del ámbito de los carrascales submediterráneos en transición a los esclerófilos y se distribuyen, principalmente, en los piedemontes de las sierras de Moncalvillo y de La Hez, además de aparecer en el piedemonte de la Sierra de Toloño (Figura 9).

En la Sierra de Moncalvillo alcanzan los $1.050 \mathrm{~m}$, para dejar paso a los escobonales-brezales mayores, y descienden hasta los $600 \mathrm{~m}$, encontrándose con un posible límite de expansión a menores cotas por el predominio del uso agrícola. De forma similar, en el piedemonte de la Sierra de La Hez ocupan una franja que desciende, puntualmente, desde $1.050 \mathrm{~m}$ hasta los $550 \mathrm{~m}$, por debajo de la cual, con menores pendientes y, de forma similar a lo que sucede en Moncalvillo, dominan los terrenos agrícolas. En la solana de Sierra de La Hez este tipo asciende hasta los $1.200 \mathrm{~m}$. En las faldas de la Sierra de Toloño se sitúan entre 700-1.150 m, llegando hasta la cumbre en mezcla con pastos herbáceos. 


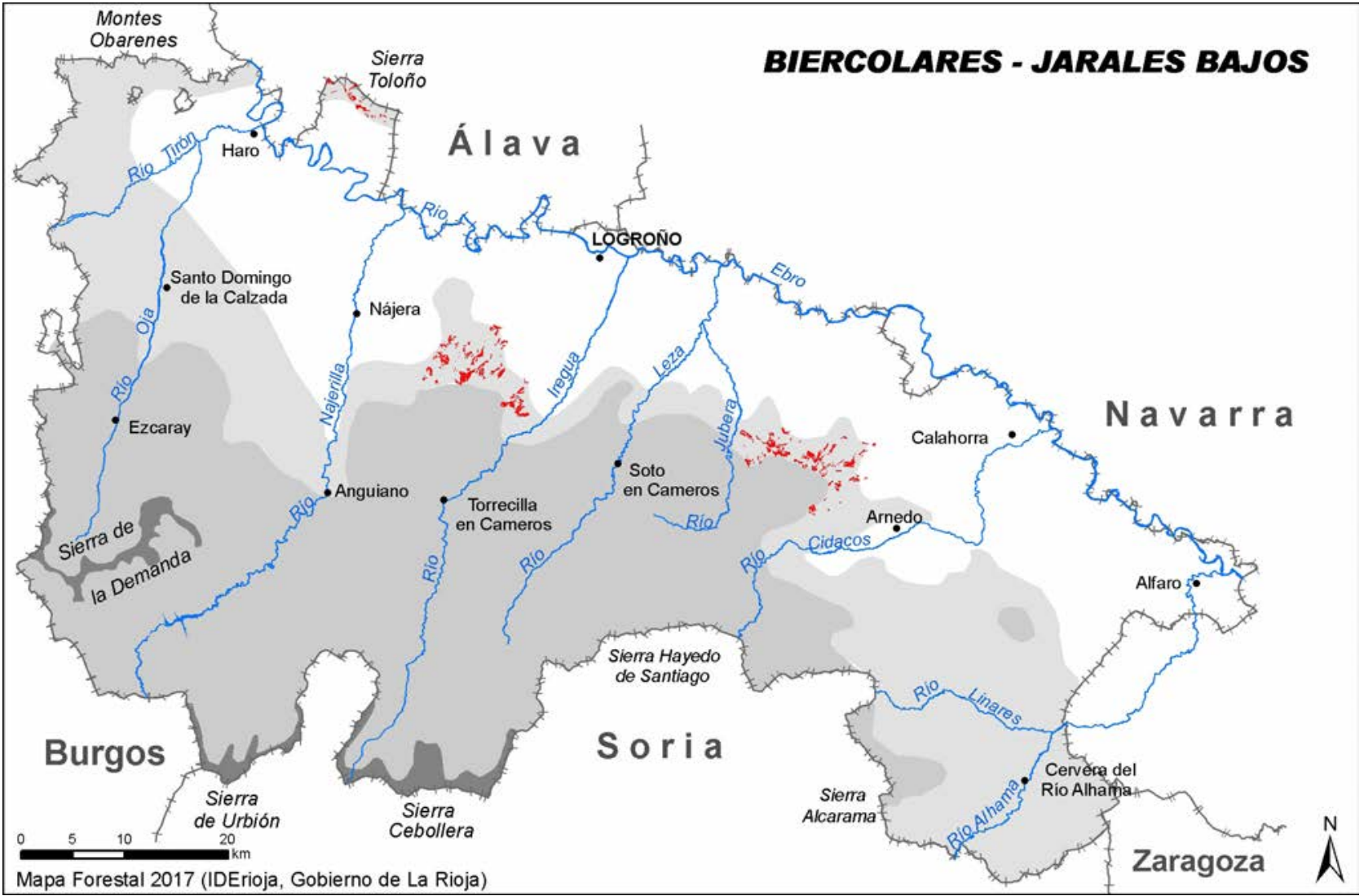

Figura 9: Distribución de los biercolares-jarales bajos en La Rioja.

Figure 9: Distribution Map of Low Heathlands (Erica, Calluna) - Low Rockrose Scrubs (Cistus) in La Rioja.

\section{Brezales mayores-jarales bajos}

De forma singular, en los enclaves montañosos más húmedos dentro del conjunto de las zonas de transición (Sierra de Moncalvillo y Montes Obarenes), aparecen los brezales mayores-jarales bajos con presencia predominante de Erica scoparia y, secundariamente, de Erica arborea en mezcla con la jara blanca Cistus albidus.

Esta agrupación mixta tiene una escasa representación superficial en La Rioja (Figura 10). En Moncalvillo, se sitúa entre 900 y $1.100 \mathrm{~m}$, mientras que en los Montes Obarenes se ubica en enclaves de altitud próxima a los $700 \mathrm{~m}$.

\section{Jarales bajos}

En estos matorrales, que aparecen en los piedemontes de transición de la mitad este de la región, el predominio corresponde a la estepa o jara blanca (Cistus albidus), que puede aparecer acompañada por la ubicua aulaga (Genista scorpius). Parece sustituir a los biercolares-jarales bajos sobre los piedemontes de clima más mediterráneo de la mitad oriental de La Rioja y sobre suelos mayoritariamente calizos.
Alcanzan una reducida superficie, pudiendo distinguirse dos ámbitos principales: los piedemontes que se extiende desde el Iregua hasta el Cidacos, y la zona de montaña media mediterránea de la cuenca del Alhama (Figura 11). Ocupan una estrecha banda situada entre los 600-700 m y los 800 m (Gatur-Yerga). En la cuenca media del Iregua (Castañares de las Cuevas) aparece un pequeño enclave en solana en torno a los $700 \mathrm{~m}$, mientras que en los piedemontes de La Rioja Baja pueden descender hasta los 550-600 m en la Mata de Galilea. En localizaciones de solana, como en Sierra de La Hez (Arnedillo) y en Peñalmonte (Préjano), se extienden entre 950 y 1.100-1.200 m. En la cuenca del Alhama bajan hasta los $700 \mathrm{~m}$ y ascienden hasta los $850 \mathrm{~m}$ en Grávalos y hasta los 950-1.000 m en las laderas del carrascal de Monegro.

\section{Aulagares}

Dentro de este tipo se incluyen las agrupaciones con aulaga, ulaga o aliaga (Genista scorpius) que abarcan diversas variantes ecológicas y corológicas (subxerófilas de media montaña y de piedemonte), así como fisonomías diversas por variedad de densidad y acompañantes. Los aulagares presentan una vasta distribución 


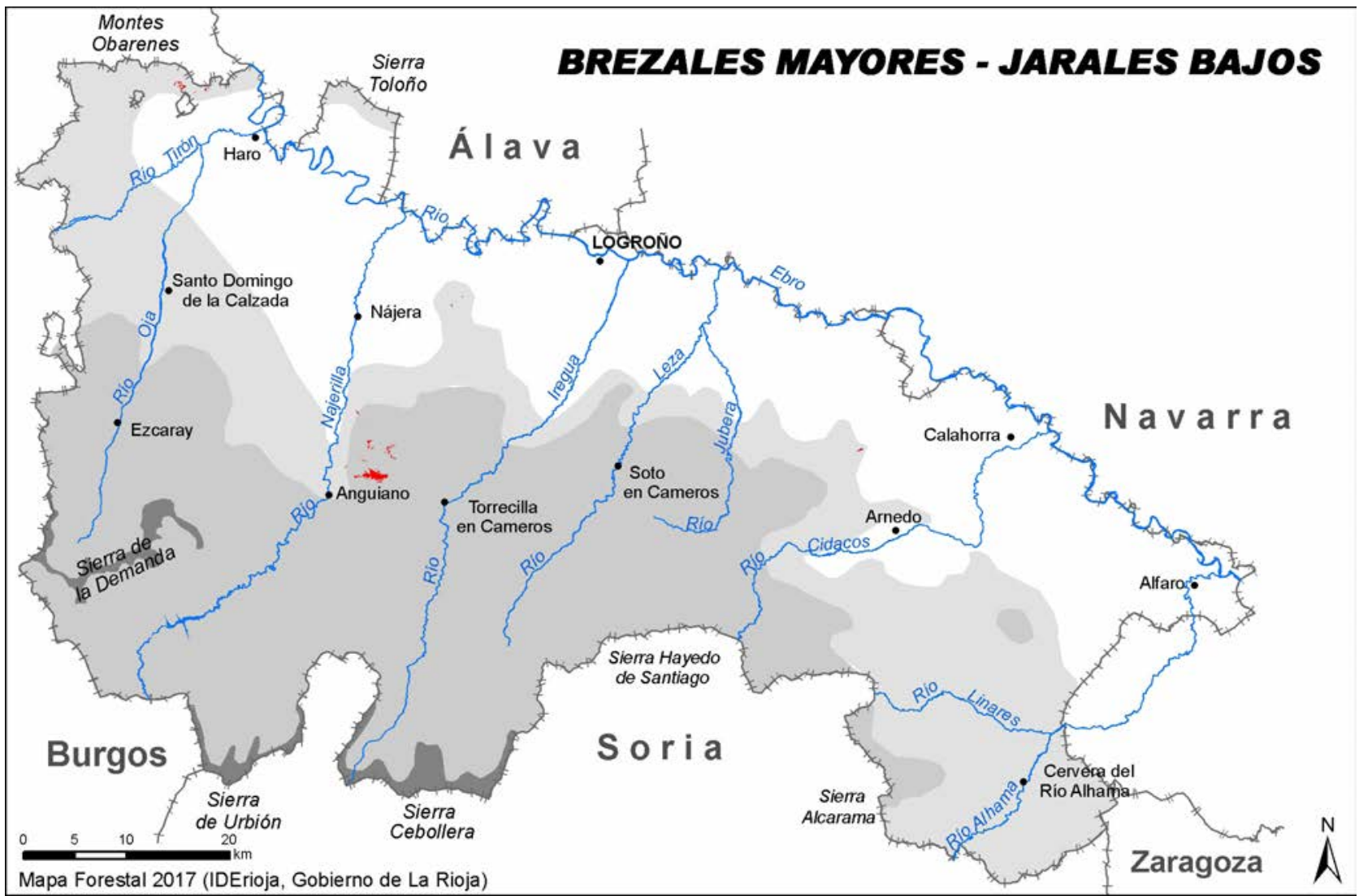

Figura 10: Distribución de los brezales mayores-jarales bajos en La Rioja.

Figure 10: Distribution Map of High Heathlands (Erica) - Low Rockrose Scrubs (Cistus) in La Rioja.

en el territorio riojano (Figura 12) y, por consiguiente, un rango altitudinal también amplio. Su carácter ubicuo les permite formar parte o imbricarse íntimamente con otros tipos, asimismo extensos, como los matorrales xerófilos basales del Valle del Ebro o los matorrales xerófilos de media montaña, que cabe incluir en los lastomato-aliagares, con mezclas de abundancia y densidad variable en las que intervienen gramíneas lastoniformes, matillas sufruticosas y la propia aulaga. Pueden distinguirse dos ámbitos principales no completamente disjuntos:

- Zona de montaña. En el ámbito montano ocupan una gran parte de los terrenos calizos, generalmente asociados a antiguas tierras de cultivo muy a menudo abancaladas, que se extienden desde la cuenca del Oja hasta la del Cidacos, llegando a altitudes considerables en la cuenca alta del Najerilla. También son abundantes en las montañas más mediteráneas de la cuenca del Alhama, siendo Genista scorpius una especie importante en la composición de los matorrales xerófilos de media montaña, característicos de esta zona de transición.

$\mathrm{Su}$ límite superior de la zona oeste varía desde $1.200 \mathrm{~m}$ en el Oja hasta $1.600 \mathrm{~m}$ de la banda caliza que atraviesa el Alto Najerilla. En las cuencas cen- trales suben hasta $1.450 \mathrm{~m}$ en el Alto Iregua y hasta $1.000 \mathrm{~m}$ en el Leza, en donde los estrepales detienen su ascenso. En las zonas de montaña más orientales llega hasta $1.300-1.350 \mathrm{~m}$ en la cuenca del Cidacos y hasta 1.100-1.200 m en la del Alhama.

- Piedemontes. La aulaga también es predominante en los piedemontes calizos desde la cuenca del Najerilla hasta la Sierra de Yerga. En su cota más baja, donde enlaza con los matorrales xerófilos basales y de los que forman forma parte, desciende hasta 600-700 m en La Rioja Alta y Media, y hasta 550$500 \mathrm{~m}$ en los piedemontes del Jubera, Cidacos y Alhama.

Relacionados con este tipo, se encuentran otros dos tipos de matorral que tienen una menor importancia superficial en La Rioja: los aulaginares (Genista hispanica), como variante más microterma e higrófila de los aulagares (cumbres de Peña Isasa); y los erizonales (Erinacea anthyllis), sobre roquedos calizos y zonas venteadas.

\section{Romerales}

Estos matorrales están dominados por el romero (Rosmarinus officinalis), con tallas y densidades varia- 


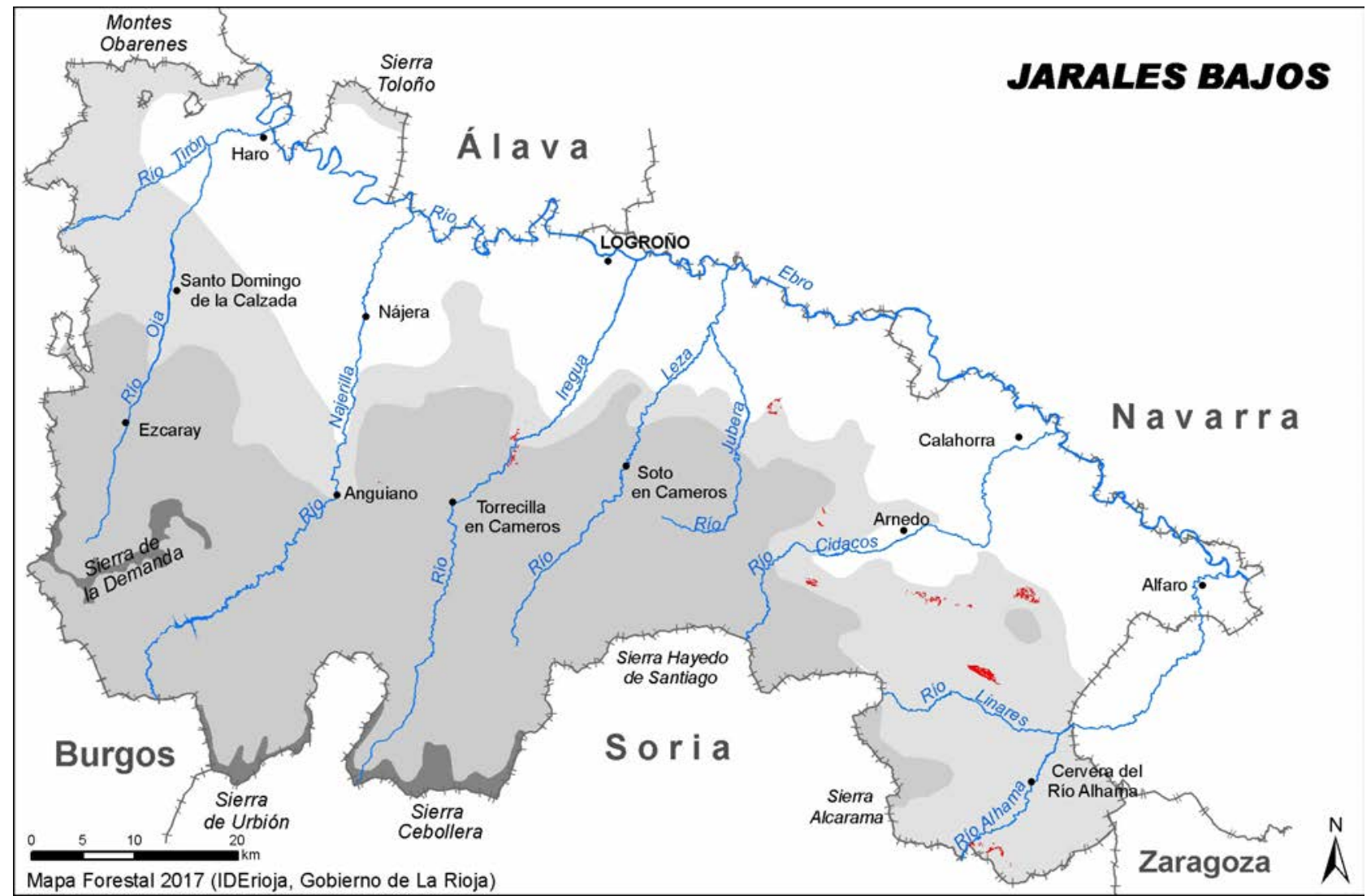

Figura 11. Distribución de los jarales bajos en La Rioja.

Figure 11: Distribution Map of Low Rockrose Scrubs (Cistus) in La Rioja.

bles en función de las características del suelo que, por lo general, aparecen ligados a calizas jurásicas en suelos con escaso desarrollo. En muchas ocasiones colonizan antiguas zonas de cultivos hoy abandonadas, tras una fase inicial de recubrimiento rápido de los aulagares, a los que sustituyen probablemente por bloqueo evolutivo si no persisten factores y agentes perturbadores (ganado, quemas).

Para la delimitación de la distribución de los romerales es posible trazar una diagonal, en sentido noroeste-sureste, desde los Montes Obarenes en La Rioja Alta hasta la cuenca del Alhama y atravesando el Valle del Ebro, en donde el dominio de los cultivos agrícolas les confiere un carácter testimonial (Figura 13). En el extremo noroeste ocupan una banda en torno a los $550 \mathrm{~m}$ en el piedemonte de los Montes Obarenes y alcanzan los 750-800 m en las laderas de la vecina Sierra de Toloño, bajando al propio río Ebro con $450 \mathrm{~m}$.

En La Rioja Media, los romerales descienden hasta el río Ebro, con la cota más baja en torno a los 350-400 m en las cercanías de Logroño. Siguiendo en sentido sureste, aparecen dos pequeños enclaves en el piedemonte del Leza (Peñas de Leza) y del Jubera (San Martín de Jubera) con 750-800 m. Ya en el Cidacos, están presentes a partir de los 500-550 m (Arnedo- Autol) para ascender hasta los $950 \mathrm{~m}$ en Arnedillo y los $1.150 \mathrm{~m}$ en la solana de Peñal- monte (Préjano). En la cuenca del Alhama, donde tienen su mayor representación en La Rioja, los romerales forman también parte de los matorrales xerófilos de media montaña, variando entre $450 \mathrm{~m}$ y $900 \mathrm{~m}$ de altitud; en la solana de Yerga llegan hasta los $1.000 \mathrm{~m}$.

\section{Matorrales xerófilos de media montaña}

En las montañas de la cuenca del Alhama (Figura 14) domina mayoritariamente el complejo denominado matorrales xerófilos de media montaña, formado por diversos matorrales calcícolas, frecuentemente en mezclas y micromosaicos intrincados, entre los que destacan: salvioesplegares (Salvia lavandulifolia-Lavandula latifolia), tomillares (Thymus zygis) y comunidades fisonómicamente afines de matas leñosas bajas, aulagares (Genista scorpius) y romerales (Rosmarinus officinalis).

Se trata de una zona de media montaña en el contexto de las sierras riojanas, con altitudes que varían entre los $450 \mathrm{~m}$ en las zonas más bajas y los $1.531 \mathrm{~m}$ en las cumbres de la Sierra de Alcarama. Sus cubiertas vegetales han sido sometidas secularmente a procesos de degradación derivada de las actividades agrícolas y ganaderas, concurriendo unas condiciones climáticas poco favorables para una rápida restauración, lo que ha producido, junto con la 


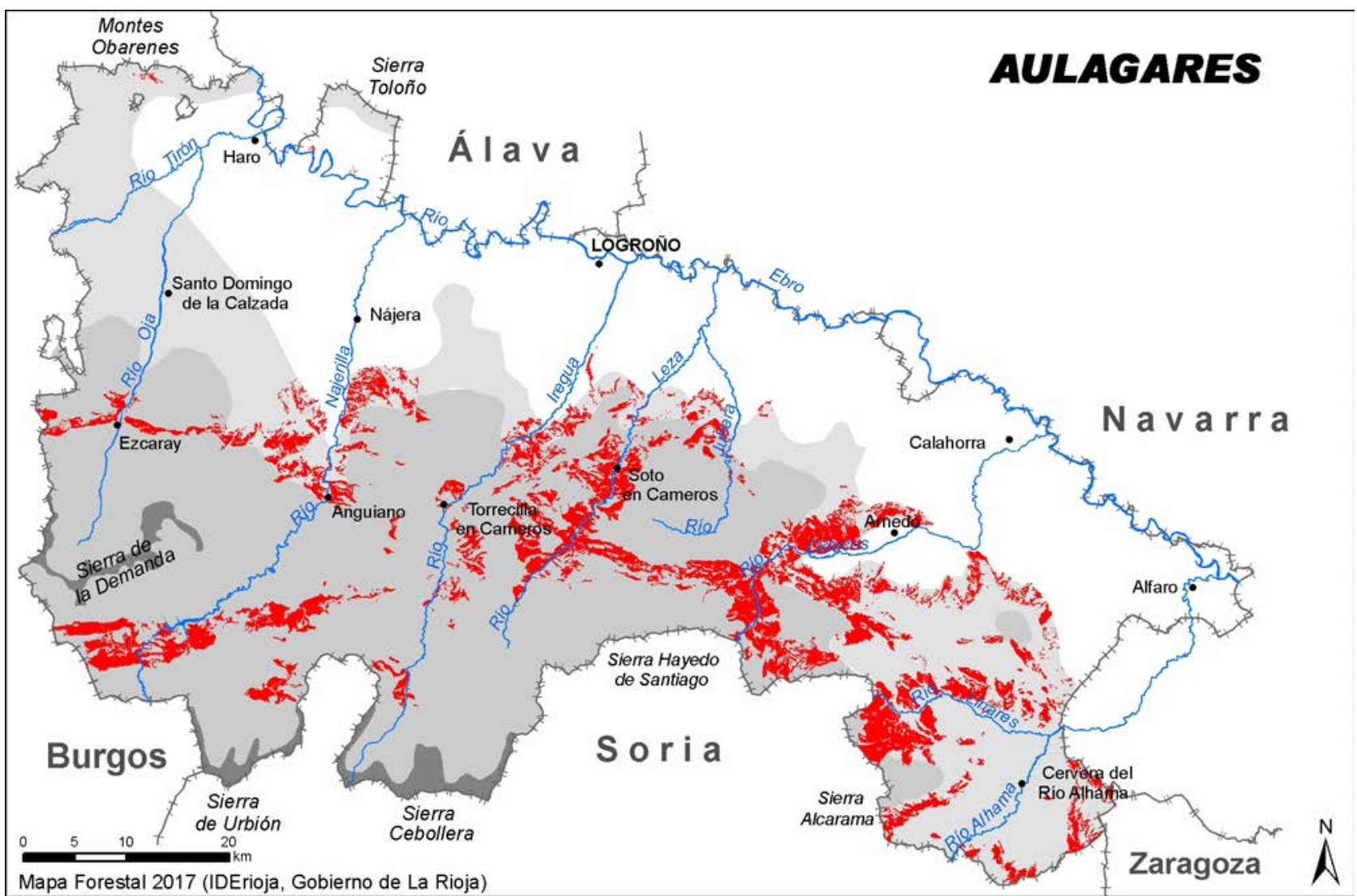

Figura 12: Distribución de los aulagares en La Rioja.

Figure 12: Distribution Map of Goarse Scrubs (Genista scorpius) in La Rioja.

erosión de las laderas, la deforestación y la estabilización de tipos de estructura (formaciones) de categoría inferior (matorrales bajos y ralos).

El conjunto de estos matorrales es además, y con el criterio adoptado en esta cartografía, exclusivo de la cuenca del Alhama, en la que llegan a dominar los espacios deforestados mencionados, en mezcla con romerales y aulagares. Su localización varía entre los $450 \mathrm{~m}$ en sus zonas más bajas y los $1.050 \mathrm{~m}$ en la Sierra de Alcarama y montes de Monegro, con una altitud media de 600-800 m en la cuenca.

\section{d) PISO MESOMEDITERRÁNEO (VALLE DEL EBRO)}

Se corresponde con las tierras del Valle del Ebro, desde La Rioja Alta a La Rioja Baja. En el conjunto del territorio hay un progresivo incremento, de oeste a este, de las condiciones de mediterraneidad y aridez. Constituyen un espacio dominado por los cultivos agrícolas, con la casi total desaparición y degradación en los escasos espacios forestales; este hecho dificulta su caracterización en lo referente a la adscripción de arbolado potencial dominante, en todo caso predominantemente del Tipo Esclerófilo (E), y a la composición de estadios de madurez intermedia.
Se ha establecido un único tipo con una denominación colectiva, matorrales xerófilos basales, en el que, evidentemente, se producirán variantes entre los extremos de la banda territorial del Valle del Ebro, desde un ombroclima seco superior en el oeste (La Rioja Alta) hasta seco inferior en el este (La Rioja Baja). El Tipo Climático-Estructural dominante en el área es el Esclerófilo (con enclaves restringidos de Subesclerófilo en La Rioja Alta y en umbrías), pero con precipitaciones que pueden rondar los $350-400 \mathrm{~mm}$ en la parte oriental, pudiendo hablarse de transición al ámbito Hiperxerófilo.

El clima general es típicamente mediterráneo de interior, definido por un invierno templado a frío, húmedo a subseco, y un periodo cálido y seco de 3 a 5 meses. Las precipitaciones medias anuales en su área actual oscilan en el entorno de los $460 \mathrm{~mm}$, con máximo en 600 y mínimo en $370 \mathrm{~mm}$.

\section{Matorrales xerófilos basales}

Dentro de este tipo genérico se engloban los siguientes tipos de matorrales calcícolas, muy relacionados y adaptados a la intensa influencia humana (pastoreo, quemas, laboreos cíclicos) en un entorno muy transformado con respecto a la vegetación más madura teóricamente posible: 


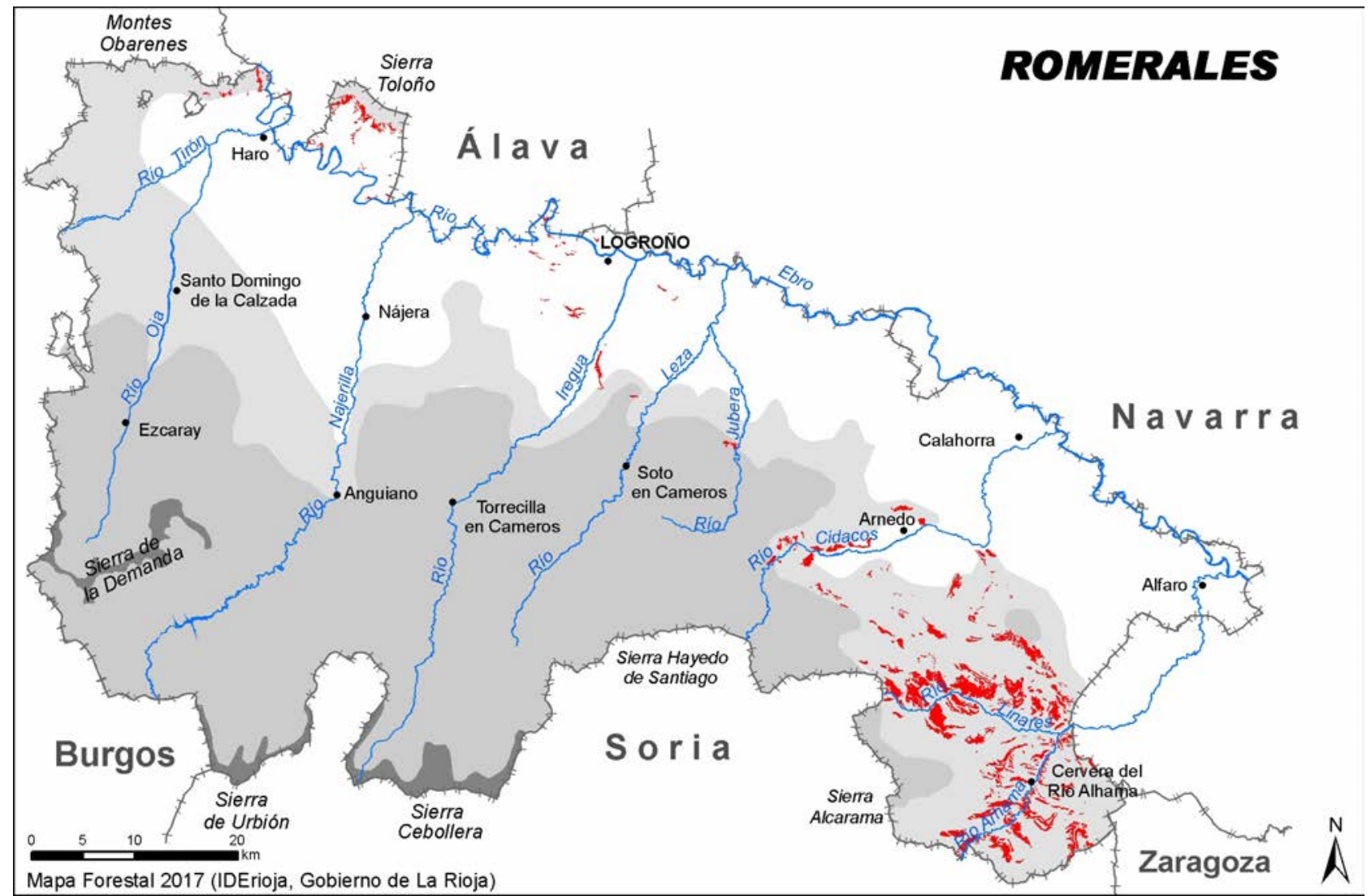

Figura 13: Distribución de los romerales en La Rioja.

Figure 13: Distribution Map Rosemary Scrubs (Rosmarinus officinalis) in La Rioja.

- Matorrales mixtos con predominio de Genista scorpius o lasto-timo-aulagares esclerófilos.

- Tomillares sensu lato (matorrales bajos y rastreros y pastizales leñosos), incluidos esplegares $\mathrm{y}$ salvio-esplegares.

Aunque de gran extensión potencial, este complejo de matorrales tiene una escasa presencia en un ámbito como el Valle del Ebro que es mayoritariamente agrícola, habiendo quedado restringida su presencia a cuestas, ribazos, cerros, etc. de forma muy fragmentada (Figura 15). Actualmente, el abandono de los terrenos agrícolas marginales y de los eriales está favoreciendo su expansión. En sentido inverso, la desaparición de la vegetación de los taludes, intercalados entre fincas agrícolas por concentraciones parcelarias, ha supuesto la pérdida de restos aún presentes hace varias décadas.

Las agrupaciones de este tipo ocupan, pues, las zonas no cultivadas del Valle del Ebro y se extienden desde las tierras más bajas de Alfaro, a $250 \mathrm{~m}$, hasta las faldas de las sierras que bordean la cuenca del Ebro. Su límite altitudinal superior es variable y está muy determinado por los procesos de ocupación del territorio, oscilando entre los 600-650 m en La Rioja Alta y Media hasta los $700 \mathrm{~m}$ a partir del Leza y Cidacos, mientras que en el piedemonte de Yerga de La Rioja Baja asciende tan sólo hasta los 550-600 m.
También tienen cierta representación superficial en el conjunto, igualmente fragmentada, de agrupaciones del tipo "otros matorrales" como los escobillares (Dorycnium pentaphyllum), dominantes en cubiertas mixtas, y los bolinares (Santolina chamaecyparisus), de carácter subnitrófilo.

\section{e) INTRAZONALES}

La intrazonalidad se refiere a la existencia de sustratos de naturaleza química limitante que impone una vegetación dominada por especies integrantes adaptadas a estas condiciones. Se exacerba en lugares con climas secos, en los que las escasas e irregulares lluvias no producen el lavado de los elementos condicionantes. Dentro de este grupo aparecen de forma mayoritaria dos tipos de matorrales (Molina Martín, 2016) que se corresponden con las siguientes unidades desarboladas: matorrales gipsófilos y matorrales halófilos y nitrófilos.

\section{Matorrales gipsófilos}

Ligados a sustratos yesosos, se han considerado los siguientes tipos de matorrales con predominio de las siguientes especies: arnacho (Ononis tridentata) y jaguar- 


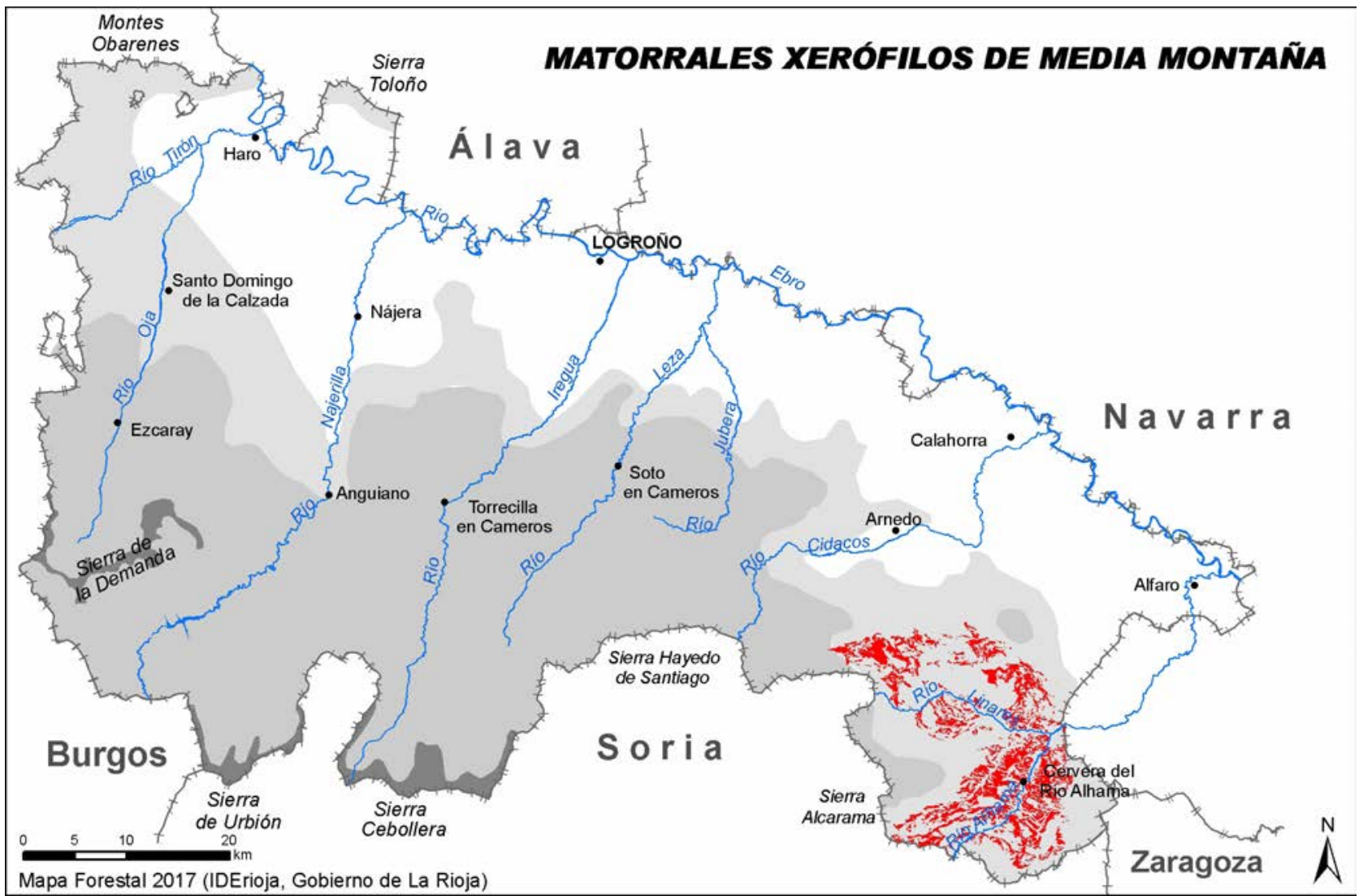

Figura 14: Distribución de los matorrales xerófilos de media montaña en La Rioja.

Figure 14: Distribution Map of Mid-Mountain Xerophile Scrub Communities -Low Rockrose Scrubs in La Rioja.

zos (Helianthemum squamatum y H. lavandulifolium). El también denominado asnallo o garbancillo, Ononis tridentata, no es una especie gipsófila estricta, por lo que puede formar parte de matorrales calcícolas mixtos en áreas próximas a los afloramientos yesosos, allí donde pueden prevalecer aulagares, esplegares o salviares ( $\mathrm{Sal}$ via lavandulifolia, especialmente frecuentes en estas situaciones), tomillares ss. 1t. o matorrales hiperxerófilos (ontinares, etc.).

Las representaciones más extensas se dan en las zonas de montaña de Viguera-Nalda-Clavijo-Ribafrecha-Lagunilla-Jubera, con altitudes entre los 500 y $800 \mathrm{~m}$, y en la cuenca del Alhama (Cervera-Aguilar) variando entre los 600 y los $900 \mathrm{~m}$, con presencia de algunos afloramientos de reducida superficie en Arnedillo. En el Valle del Ebro se encuentran de forma puntual en La Rioja Alta (San Millán de Yécora, Treviana, Ochánduri, Tormantos, Leiva, etc.), en La Rioja Media (Arrúbal-Alcanadre) y en La Rioja Baja (Grávalos).

La representación real cartografiable corresponde mayoritariamente a los matorrales gipsófilos ligados a lomas y cerros en zonas externas al Valle (yesos no terciarios), por encontrarse los yesares de la depresión del Ebro muy influidos por la contigüidad de actividades agrícolas (Figura 16).

\section{Matorrales halófilos y nitrófilos}

Dentro de este amplio grupo de encuadran diversos tipos agrupados del siguiente modo:

- Matorrales halonitrófilos + hiperxerófilos: sisallares (Salsola vermiculata), ontinares (Artemisia herba-alba), bojares (Artemisia campestris subsp. glutinosa) y orgazales (Atriplex halimus).

- Matorrales halohidrófilos en salobrales estacionales: espartizales-albardinales halohidrófilos (Lygeum spartum), sosares vivaces (Suaeda vera) y terofíticos (Salicornia ramosissima).

Están asociados claramente a las condiciones ambientales del piso Mesomediterráneo en el Valle del Ebro, donde las precipitaciones medias anuales no superan los 430-450 mm con una mínima de, incluso, $370 \mathrm{~mm}$ en algunos enclaves. En esas condiciones de clima semiárido, las sales no se disuelven y se incorporan al complejo del suelo que, además, suele ser arcilloso y con escasa capacidad de drenaje. En depresiones y vaguadas endorreicas, márgenes de charcas y balsas, la escorrentía queda impedida y además se produce el depósito de los materiales salinos de las cuestas vertientes. 


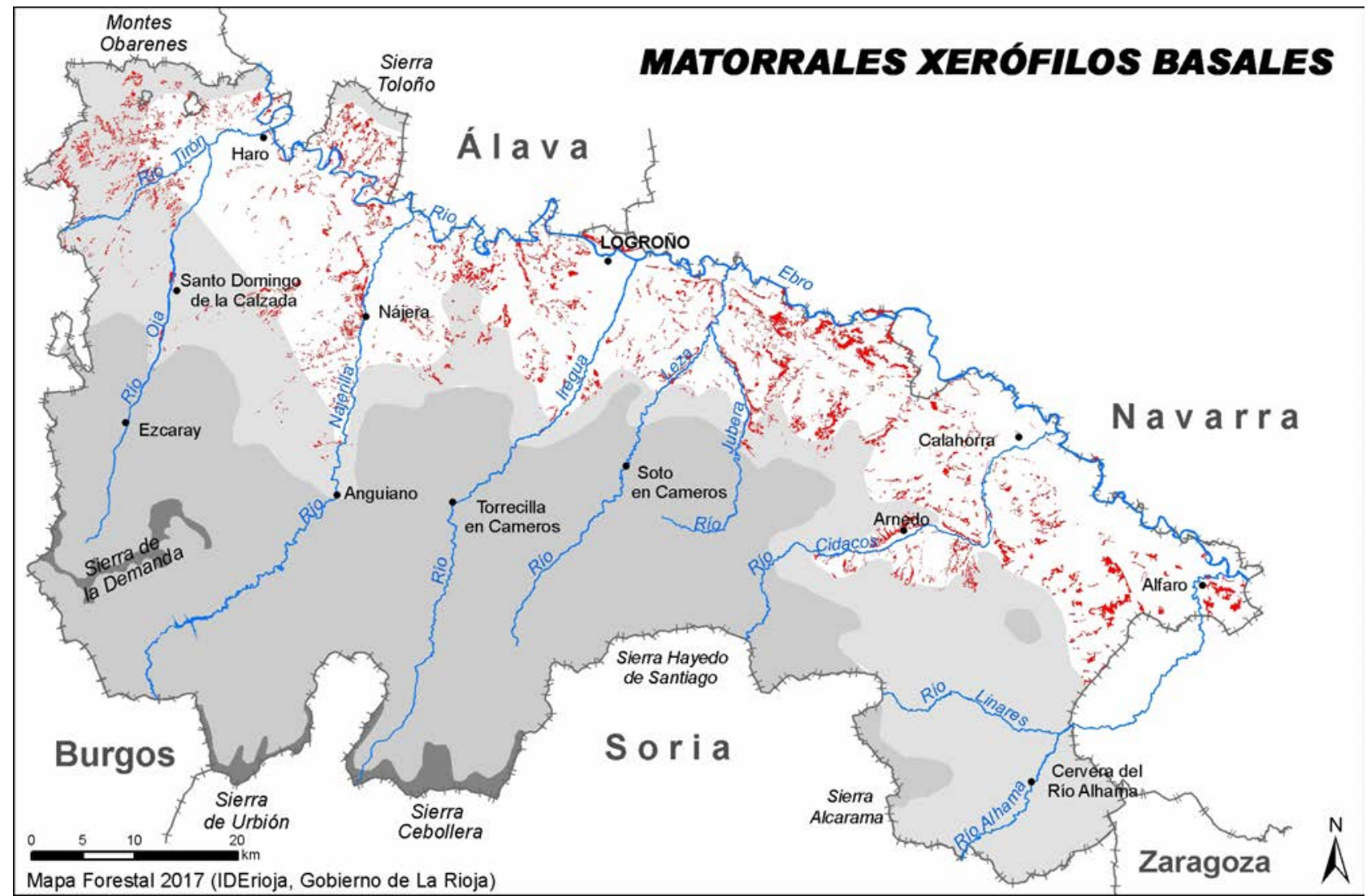

Figura 15: Distribución de los matorrales xerófilos basales en La Rioja.

Figure 15: Distribution Map of Basal Xerophile Scrub Communities in La Rioja.

Estos matorrales ocupan las tierras bajas del Valle del Ebro con cierta presencia, que ha sido cartografiada (Figura 17), a partir de la cuenca del Leza hacia el este: Agoncillo-Arrúbal, Ausejo-Alcanadre (Trasumo, El Salobre), Pradejón (Costeras, Yasa del Arco, La Maja), Calahorra (Perdiguero, Recuenco), Alfaro (La Molineta, Llasa de Cofin). También aparecen en algunos enclaves de La Rioja Alta y Media, como en la Laguna de Hervías, Lagunas de La Mata y La Madrileña (San Asensio), La Grajera y en los montes Cantabria y El Corvo (Logroño).

\section{Discusión}

\subsection{Comparación con el Mapa de Matorrales de La Rioja de 1990}

De la comparación del nuevo Mapa de Matorrales dominantes con el realizado en el año 1990 (Arizaleta Urarte et al., 1990.) pueden deducirse una serie de diferencias que permiten una mejor caracterización de estas formaciones leñosas. De entrada, y aplicando la metodología propuesta conjuntamente con una fotointerpretación más detallada, se ha pasado de 8 a 16 tipos principales de matorral, pudiendo extraerse las siguientes consideraciones:
- Definición e individualización de la agrupación matorral de alta montaña, adaptado a las condiciones extremas de las cumbres más elevadas. Este tipo se segrega como tal de los brezales mayores de Erica australis y/o Erica arborea de las zonas más altas, con dominios potenciales territorialmente contiguos.

- Definición de la nueva variante brezales mayores de Erica arborea y/o E. scoparia dentro del amplio grupo de los brezales mayores, con presencia del brezo más mediterráneo (E. scoparia) en los piedemontes que van desde el extremo oeste (Montes Obarenes) hasta el este (Sierra de Yerga), pasando por las laderas de la Sierra de Moncalvillo que vierten hacia el Najerilla en mezcla con jarales bajos.

- Definición de la agrupación mixta escobonales-brezales mayores, a modo de transición entre el dominio de los brezales mayores y los propios escobonales, generalmente de cotas más bajas, con Erica arborea como especie de vínculo entre ambas.

- Consideración del tipo de los romerales, lo que facilita, por una parte, una mejor concreción dentro del amplio grupo de matorrales xerófilos de media montaña y, por otra, singulariza su presencia significativa en las faldas de los Montes Obarenes y de la Sierra de Toloño. 


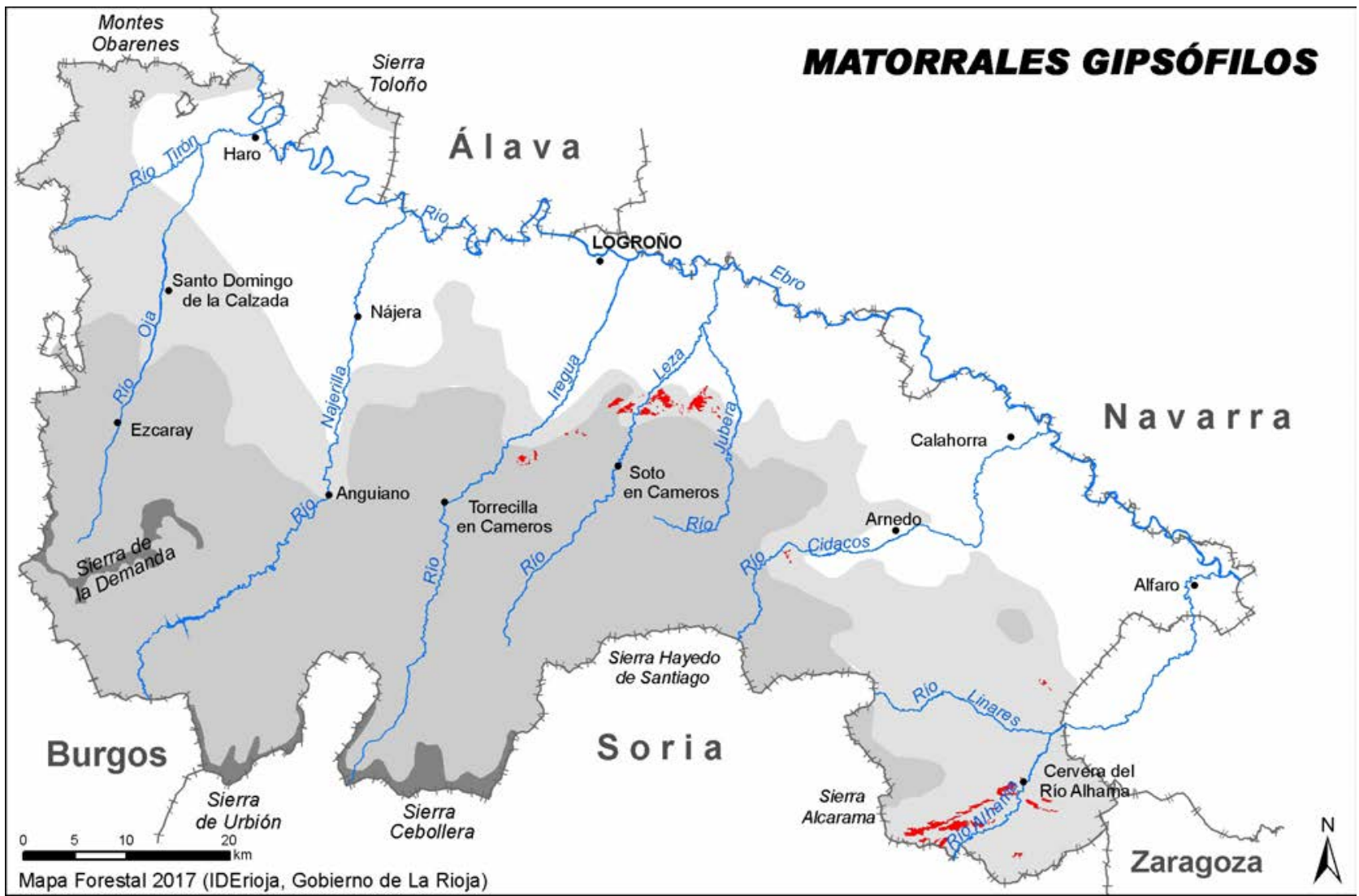

Figura 16: Distribución de los matorrales gipsófilos en La Rioja.

Figure 16: Distribution Map Gypsophile Scrubs in La Rioja.

- Ampliación de la superficie asignada a los brezales mayores de alta y media montaña de Erica australis y/o Erica arborea a nuevos ámbitos montanos en la cuenca del Najerilla (Cerro Urbaña), en el interfluvio Najerilla-Iregua (San Cristóbal y Sierra de Moncalvillo) y en la cuenca del Iregua (Mojón Alto y Peña Yerre).

- Extensión actualizada de los biercolares a amplias zonas de montaña sobre suelos silíceos o descarbonatados; así, por ejemplo, en las estribaciones de la Sierra de Urbión, en los puertos de Las Viniegras y de Canto Hincado en el Najerilla, y en los interfluvios de Serradero o entre ambos Cameros. En general, sustituyen a tipos asignados en el mapa anterior a los aulagares montanos en los suelos calizos y a los escobonales en los suelos silíceos.

- Mejora de la representación del área de distribución de los bujedos con reducción significativa de su superficie en las zonas altas de la Sierra de Toloño y en los piedemontes del Iregua.

- Diferenciación de los piedemontes sobre suelos silíceos o calizos lavados a lo largo del gradiente oeste-este, resultando tres agrupaciones diferenciadas: biercolares en La Rioja Alta, biercolares-jarales bajos en La Rioja Media y jarales bajos con o sin aulaga en La Rioja Baja.
- Respecto a este último nuevo tipo (jarales bajos de Cistus albidus), delimitación de su área, muy ligada a los aulagares y que, además de su presencia en los piedemontes, penetra puntualmente a altitudes medias en las montañas de la cuenca del Alhama.

\section{Conclusiones finales}

Como resultado de este trabajo se ha obtenido un nuevo Mapa de los Matorrales dominantes de La Rioja que permite tener una visión general de la distribución de las principales formaciones leñosas bajas en la geografía riojana, corrigiendo, actualizando y mejorando la cartografía existente hasta el momento (Arizaleta Urarte et al., 1990), que fue realizada con materiales y medios más modestos.

Mediante la aplicación del concepto de "matorrales dominantes" se realiza una aproximación cartográfica de mayor resolución temática dentro de lo factible con un esfuerzo de fotointerpretación no muy elevado, teniendo en cuenta las dificultades inherentes para elaborar una cartografía muy detallada de los matorrales a causa de los problemas mencionados relativos a su caracterización, denominación y delimitación, a la frecuencia de sus mezclas y a su gran variabilidad espacial y temporal. 


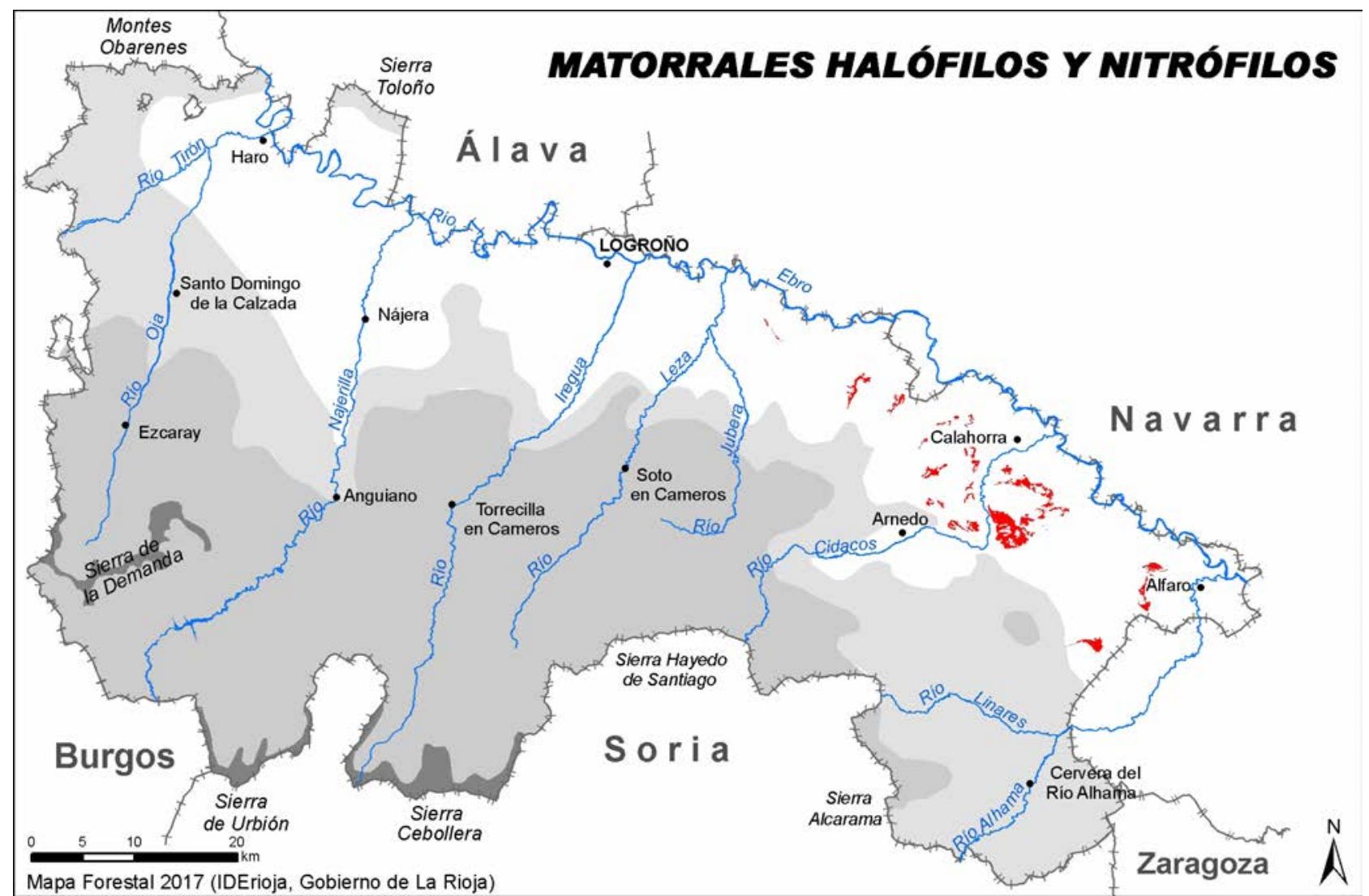

Figura 17: Distribución de los matorrales halófilos y nitrófilos en La Rioja.

Figure 17: Distribution Map of Halophile and Nitrophile Scrubs in La Rioja.

Una vez realizado el Mapa de Matorrales dominantes, se ha conseguido representar, mediante su solape con el Mapa de Bosques de La Rioja, la distribución de los tipos de matorral existentes y representativos del complejo "matorral-pastos". En este sentido y, en tanto no se avance en una cartografía más detallada con apoyo sistemático de prospecciones de campo, la delimitación establecida por el Mapa de Matorrales dominantes permite asignar por defecto, en las bases de datos asociadas, las categorías de los campos que describen las formaciones de matorral presentes, acercándose a la optimización de los recursos y medios hoy por hoy disponibles.

A partir de esta caracterización preliminar de las superficies leñosas desarboladas y mediante la toma directa de datos in situ será posible avanzar en la mejora del Mapa Forestal de La Rioja, tanto en la tipificación de las formaciones de matorral como, en una fase ulterior, en la caracterización de las comunidades de pastos herbáceos y su relación con las cubiertas leñosas con las que están asociados en dinámicas naturales o antrópicas.

Por último, se plantean las siguientes líneas de investigación:

- Delimitación precisa de la distribución de los brezales de Erica scoparia, que, frecuentemente, apa- recen mezclados con Erica arborea en las zonas de piedemonte.

- Caracterización de los matorrales xerófilos basales y de las variantes asociadas al gradiente climático existente, oeste-este, entre La Rioja Alta y La Rioja Baja.

- Caracterización de los matorrales xerófilos de media montaña en la cuenca del Alhama, orográficamente marcada por el efecto Foehn y por su posición de "hoya" rodeada por líneas de cumbres de media altitud $(1.000 \mathrm{~m})$, lo que acentúa su carácter mediterráneo y que ha estado sometida a una deforestación histórica $\mathrm{y}$ generalizada.

- Interpretación de los jarales bajos de Cistus albi$d u s$ en su ámbito territorial, que se extiende desde los piedemontes en la cuenca del Najerilla hasta su aparición en las montañas medias de la cuenca del Alhama (Monegro).

- Definición de niveles y subniveles evolutivos de los biercolares en las zonas de montaña y su relación con la actividad ganadera.

- Detección de las causas de inexistencia de escobonales en la mayor parte de la zona montañosa del Leza y del Jubera. 


\section{8 • R. FERNÁNDEZ ALDANA, C. LÓPEZ LEIVA, T. BAÑARES GARCÍA}

\section{Referencias}

Arizaleta Urarte, J.A., Fernández Aldana, R., Lopo Carramiñana, L., 1990. Los matorrales de La Rioja. Zubía, 8: 83-122. Logroño.

Fernández Aldana, R., 2015. Mapa de los bosques de La Rioja. Gobierno de La Rioja. Logroño.

IDErioja, 2015. Mapa forestal de La Rioja. Gobierno de La Rioja.

López Leiva, C., 2008. Informe del Mapa Forestal de España a escala 1:50.000 para las comunidades autónomas de Galicia, Asturias, Cantabria, Castilla y León, La Rioja, Madrid, Extremadura, Murcia e Islas Canarias. DGCONA-Ministerio de Medio Ambiente/Universidad Politécnica de Madrid.

López Leiva, C., 2018. Tipología de cubiertas forestales no arboladas para su aplicación en la cartografía forestal del territorio ibérico-balear. Cuantificación superficial de su significatividad. $7^{\circ}$ Congreso Forestal Español. Plasencia.

Molina Martín, C., 2016. Trabajo monográfico sobre hábitats singulares y salinos del Valle del Ebro. (Proyecto de actualización y revisión de la cartografía de hábitats naturales de interés comunitario en La Rioja y su incorporación al Banco de Datos de la Biodiversidad de La Rioja). TRAGASATEC y Gobierno de La Rioja.
Rivas-Martínez, S., 1987. Memoria del Mapa de Series de Vegetación de España. ICONA. Ministerio de Agricultura, Pesca y Alimentación. Madrid.

Rivas Martínez, S. y colaboradores, 2007. Memoria del Mapa de Vegetación Potencial de España - Parte I. Mapa de series, geoseries y geopermaseries de vegetación de España. Itinera Geobotanica, 17: 5-436.

Ruiz de la Torre, J., 1981. Matorrales. En: Tratado del medio natural, II: 501-541. Universidad Politécnica de Madrid. Madrid.

Ruiz de la Torre, J. (coord.), 1990. Memoria General del Mapa Forestal de España a escala 1:200.000. ICONA. Ministerio de Agricultura, Pesca y Alimentación. Madrid.

Ruiz de la Torre, J., (coord.), 1998. Mapa Forestal de España a escala 1:200.000. Hoja 6-3 Logroño. Ministerio de Agricultura, Pesca y Alimentación y Ministerio de Medio Ambiente. Madrid.

Ruiz de la Torre, J. (coord.), 2000. Mapa Forestal de España a escala 1: 1.000.000. Ministerio de Medio Ambiente. Madrid.

San Miguel Ayanz, A, Roig Gómez, S., Cañellas Rey de Viñas, I., 2004. Fruticeticultura. Gestión de arbustedos y matorrales. Compendio de Selvicultura Aplicada en España. DGCONA. Madrid. 


\section{Anexo 1}

Correspondencias entre los tipos considerados en la cartografía de matorrales de La Rioja (2018) y la Taxonomía jerarquizada de cubiertas forestales no arboladas de España (López Leiva, 2008, 2017). Los códigos numéricos son los utilizados en las unidades de esta última clasificación con la denominación más aproximada a la de los tipos de matorra de La Rioja (pt.=en parte)

Correspondences among types considered in the map of scrub communities of La Rioja (2018) and the Hierarchical Taxonomy of Non Arboreous Plant Covers of Spain (López Leiva, 2008, 2018). The numerical codes are the same ones used for the categories of the latter classification, with the most approximate names to the designation of the scrub types used here

\begin{tabular}{|c|c|c|c|}
\hline Tipos de matorral & \multicolumn{3}{|c|}{ Unidades en Taxonomía jerarquizada de cubiertas vegetales no arboladas de España } \\
\hline \multirow{3}{*}{ Matorrales de alta montaña } & \multicolumn{3}{|c|}{ Enebrales rastreros de altura (Juniperus communis alpina) 212} \\
\hline & \multicolumn{3}{|c|}{$\begin{array}{l}\text { Brezales orófilos 221 } \\
\text { [Brecinales/biercolares de altura (Calluna vulgaris)] }\end{array}$} \\
\hline & \multicolumn{3}{|c|}{ Piornales de montaña (Cytisus oromediterraneus) 2311} \\
\hline & \multicolumn{3}{|c|}{ Tojares (Ulex europaeus) 2412} \\
\hline & \multicolumn{3}{|c|}{ Brezales hidrófilos de trampal 2122} \\
\hline & \multicolumn{3}{|c|}{ Espinares caducifolios (incluye espinares mixtos, escaramujales, endrinales, zarzales etc.) en ámbito húmedo } \\
\hline \multirow{3}{*}{$\begin{array}{c}\text { Brezales mayores } \\
\text { (variante mesófila de alta y media } \\
\text { montaña, dominada por Erica australis } \\
\text { y presencia significativa de Erica } \\
\text { arborea) }\end{array}$} & \multirow{4}{*}{$\begin{array}{c}\text { Brezales + mesófilos } \\
\text { (Incluye manifestaciones de } \\
\text { Vaccinium myrtillus } 2231 \text { y } \\
\text { Arctostaphylos uva-ursi 2261) }\end{array}$} & \multirow{3}{*}{$\begin{array}{c}\text { Brezales mayores + mesófilos oligoespecíficos } \\
\text { Incluye frec. brezal-helechares (Pterdium } \\
\text { aquilinum) }\end{array}$} & $\begin{array}{l}\text { Brezales mesófilos orófilos de Erica australis } \\
2252\end{array}$ \\
\hline & & & $\begin{array}{c}\text { Brezales mesófilos mixtos (Erica arborea-Erica } \\
\text { australis) } 225\end{array}$ \\
\hline & & & Brezales mesófilos de Erica arborea 2251 \\
\hline \multirow[t]{2}{*}{$\begin{array}{l}\text { Biercolares } \\
\text { (variante mesófila, excepcionalmente } \\
\text { subxerófila) }\end{array}$} & & $\begin{array}{c}\text { Brezales bajos/biercolares + mesófilos } \\
\text { oligoespecíficos }\end{array}$ & $\begin{array}{l}\text { Brezales/biercolares con Erica vagans, } \\
\text { E. cinerea, Calluna vulgaris, Genista hispanica } \\
\text { etc., (a veces. G. scorpius en solanas) } 2253\end{array}$ \\
\hline & \multicolumn{3}{|c|}{ Aulaginares u Olaguinares (Genista hispanica) 2431} \\
\hline $\begin{array}{c}\text { Escobonales-brezales mayores } \\
\text { (variante mesófila, de montaña, con } \\
\text { Erica arborea y, ocasionalmente, } \\
\text { Erica australis) }\end{array}$ & \multirow{4}{*}{$\begin{array}{l}\text { Escobonales }+ \text { mesófilos } \\
232 \text { pt. }\end{array}$} & $\begin{array}{c}\text { Escobonales + mesófilos mixtos: Escobonales- } \\
\text { brezales mayores }\end{array}$ & $\begin{array}{c}\text { Escobonales }+ \text { mesófilos con E. arborea } \\
\text { y/o E. australis }\end{array}$ \\
\hline \multirow{3}{*}{$\begin{array}{c}\text { Escobonales } \\
\text { (variante mesófila) }\end{array}$} & & \multirow{3}{*}{ Escobonales + mesófilos oligoespecíficos } & $\begin{array}{l}\text { Escobonales mesófilos mixtos (Genista florida, } \\
\text { Cytisus spp. pl.) } 232\end{array}$ \\
\hline & & & Escobonales mesófilos de Genista florida 2331 \\
\hline & & & $\begin{array}{l}\text { Escobonales mesófilos de Cytisus scoparius } \\
2322\end{array}$ \\
\hline $\begin{array}{l}\text { Brezales mayores } \\
\text { (variante submesófila y subxerófila, }\end{array}$ & \multirow{3}{*}{$\begin{array}{l}\text { Brezales de submesófilos } \\
\text { a subxerófilos }\end{array}$} & \multirow{3}{*}{ Brezales mayores submesófilos o subxerófilos } & $\begin{array}{l}\text { Brezales mixtos de Erica arborea y Erica } \\
\text { scoparia } 225\end{array}$ \\
\hline de media montaña y de piedemonte, & & & Brezales submesófilos de Erica arborea 2251 \\
\hline $\begin{array}{l}\text { con predominio de Erica arborea y, } \\
\text { localmente, de E. scoparia) }\end{array}$ & & & $\begin{array}{l}\text { Brezales submesófilos y subxerófilos de Erica } \\
\text { scoparia } 2256\end{array}$ \\
\hline
\end{tabular}




\begin{tabular}{|c|c|c|c|}
\hline Tipos de matorral & \multicolumn{3}{|c|}{ Unidades en Taxonomía jerarquizada de cubiertas vegetales no arboladas de España } \\
\hline \multirow{2}{*}{$\begin{array}{l}\text { Escobonales-brezales mayores } \\
\text { (variante submesófila o subxerófila, de } \\
\text { montaña y de piedemonte, con Erica } \\
\text { scoparia en piedemonte y, en menor } \\
\quad \text { medida, Erica arborea) }\end{array}$} & \multirow{2}{*}{\multicolumn{2}{|c|}{ Escobonales submesófilos a subxerófilos mixtos }} & $\begin{array}{l}\text { Escobonales submesófilos a subxerófilos mixtos } \\
\text { con Erica scoparia (2256) }\end{array}$ \\
\hline & & & $\begin{array}{l}\text { Escobonales submesófilos a subxerófilos mixtos } \\
\text { con Erica arborea (2251) }\end{array}$ \\
\hline \multirow[t]{3}{*}{ Estrepales } & Est(r)epales y matorr & s con predominio de Cistus laurifolius & Estepares de Cistus laurifolius 2511 \\
\hline & \multicolumn{3}{|c|}{ Espinares caducifolios (incluye espinares mixtos, escaramujales, endrinales, zarzales etc.) en ámbito submediterráneo 121} \\
\hline & \multicolumn{3}{|c|}{$\begin{array}{c}\text { Manifestaciones de arbustedos caducifolios (setos inermes y arbustedos + rupícolas: Cornus sanguinea, Euonymus europaeus, } \\
\text { Viburnum lantana. Ligustrum vulgare) } 122\end{array}$} \\
\hline Bujedos & \multicolumn{3}{|c|}{$\begin{array}{c}\text { Bujedos (Buxus sempervirens) } 131 \\
\text { Inlcuye manifestaciones de Amelanchier ovalis } \\
\text { Incluye manifestaciones de arbustedos caducifolios (setos y arbustedos + rupícolas: Cornus sanguinea, Euonymus europaeus, } \\
\text { Viburnum lantana. Ligustrum vulgare) } \\
\text { Inlcluye sabinares de sabina negra (rupícolas) (Juniperus phoenicea) }\end{array}$} \\
\hline \multirow{2}{*}{$\begin{array}{l}\text { Escobonales } \\
\text { (variante de zonas de transición, } \\
\text { submesófilos o subxerófilos) }\end{array}$} & \multirow{2}{*}{\multicolumn{2}{|c|}{ Escobonales subxerófilos mixtos }} & $\begin{array}{l}\text { Escobonales submediterráneos de Genista } \\
\text { florida (solanas, laderas rocosas) } 2331\end{array}$ \\
\hline & & & $\begin{array}{l}\text { Escobonales submediterráneos de Cytisus } \\
\text { scoparius } 2322\end{array}$ \\
\hline $\begin{array}{l}\text { Brezales mayores-jarales bajos } \\
\text { (variante de piedemonte con Erica } \\
\text { scoparia, Cistus albidus y, en menor } \\
\text { medida, Erica arborea) }\end{array}$ & \multirow[b]{2}{*}{$\begin{array}{l}\text { Biercolares/brezales } \\
\text { subxerófilos mixtos }\end{array}$} & Brezales mayores subxerófilos & $\begin{array}{c}\text { Brezales de E. scoparia }+ \text { Cistus albidus y Erica } \\
\text { arborea (2256) }\end{array}$ \\
\hline Biercolares -jarales bajos & & Biercolares/brezales bajos subxerófilos & $\begin{array}{l}\text { Brezales/biercolares bajos subxerófilos } \\
\text { (Erica vagans, Erica cinerea, Calluna vulgaris, } \\
\text { Cistus albidus, Lavandula stoechas, Cistus } \\
\text { salviifolius...) } 2253 \\
\text { Incluye una variante subtermófila con Erica } \\
\text { scoparia } \\
\text { (a veces en contacto o mezcla con aulagares } \\
\text { submediterráneos y sus derivados - } \\
\text { escobillares-) } \\
\text { (Incluye manifestaciones de Arctostaphylos } \\
\text { uva-ursi) }\end{array}$ \\
\hline \multirow{2}{*}{$\begin{array}{c}\text { Jarales bajos } \\
\text { (con o sin presencia de aulagas) }\end{array}$} & \multirow{2}{*}{\multicolumn{2}{|c|}{ Jarales bajos (Cistus albidus y/o C. salviifolius) 2525, 2521}} & Jarales bajos sin aulaga (G, scorpius) \\
\hline & & & Jarales bajos con aulaga (G. scorpius) \\
\hline
\end{tabular}




\begin{tabular}{|c|c|c|c|}
\hline Tipos de matorral & \multicolumn{3}{|c|}{ Unidades en Taxonomía jerarquizada de cubiertas vegetales no arboladas de España } \\
\hline $\begin{array}{c}\text { Aulagares } \\
\text { (variante subxerófila, de montaña y de }\end{array}$ & \multirow{3}{*}{$\begin{array}{l}\text { Aulagares (Genista scorpius) } \\
\qquad 2432 \text { y } 2652\end{array}$} & \multicolumn{2}{|c|}{ Aulagares subxerófilos (Genista scorpius) } \\
\hline \multirow{2}{*}{$\begin{array}{l}\text { Matorrales xerófilos de media } \\
\text { montaña }\end{array}$} & & $\begin{array}{l}\text { Matorrales mixtos con predominio de Genista } \\
\text { scorpius o lasto-timo-aulagares } \\
\text { sub-mediterráneos }\end{array}$ & $\begin{array}{l}\text { Puede incluir erizonales de Erinacea anthyllis } \\
\text { Pueden incluir manifestaciones de }\end{array}$ \\
\hline & & $\begin{array}{c}\text { Tomillares s. l. (matorrales bajos y rastreros y } \\
\text { pastizales leñosos) en ámbito submediterráneo, } \\
\text { incluidos salvio-esplegares (Lavandula latifolia, } \\
\text { Salvia lavandulifolia) }\end{array}$ & $\begin{array}{c}\text { Incluyen escobillares (Dorycnium } \\
\text { pentaphyllum), bolinares (Santolina } \\
\text { chamaecyparissus) }\end{array}$ \\
\hline $\begin{array}{c}\text { Romerales } \\
\text { (variante supra-mesomediterránea) }\end{array}$ & \multicolumn{3}{|c|}{$\begin{array}{c}\text { Matorrales mixtos con predominio de Rosmarinus officinalis en ámbito submediterráneo } 261 \\
\text { Pueden incluir manifestaciones de Arctostaphylos uva-ursi) }\end{array}$} \\
\hline $\begin{array}{l}\text { Romerales } \\
\text { (variante mesomediterránea) }\end{array}$ & \multicolumn{3}{|c|}{ Matorrales mixtos con predominio de Rosmarinus officinalis esclerófilos 261} \\
\hline \multirow{2}{*}{ Matorrales xerófilos basales } & \multicolumn{3}{|c|}{$\begin{array}{l}\text { Matorrales mixtos con predominio de Genista scorpius o lasto-timo-aulagares esclerófilos } 2432 \text { y } 2652 \\
\text { Incluyen escobillares (Dorycnium pentaphyllum), bolinares (Santolina chamaecyparissus) }\end{array}$} \\
\hline & \multicolumn{3}{|c|}{ Tomillares s.l. (matorrales bajos y rastreros y pastizales leñosos) en ámbito submediterráneo 265, 2652} \\
\hline \multirow{6}{*}{ Matorrales gipsófilos } & \multirow{9}{*}{$\begin{array}{l}\text { Matorrales hiperxerófilos } \\
\text { e intrazonales gipsófilos }\end{array}$} & \multicolumn{2}{|c|}{ Lasto-timo-aliagar hiperxerófilo y en transición a gipsófilo 2652} \\
\hline & & \multicolumn{2}{|c|}{ Matorrales mixtos hiperxerófilos (frec. con Lygeum spartum) 28, 352} \\
\hline & & \multirow{2}{*}{ Sisallar-ontinares } & Sisalllares (Salsola vermiculata) 2841 \\
\hline & & & Ontinares (Artemisia herba-alba) 2681 \\
\hline & & \multirow{2}{*}{ Matorrales gipsófilos } & Matorral gipsófilo mixto 282 \\
\hline & & & Arnachales (Ononis tridentata) 2821 \\
\hline \multirow{3}{*}{ Matorrales halófilos y nitrófilos } & & \multicolumn{2}{|c|}{ Matorrales haloxerófilos 284} \\
\hline & & \multicolumn{2}{|c|}{ Bojares (Artemisia campestris, glutinosa) 268} \\
\hline & & \multicolumn{2}{|c|}{ Matorrales (halo)nitrófilos 288} \\
\hline
\end{tabular}

